Please note that this manuscript has been published in ISPRS Journal of Photogrammetry and Remote Sensing http://dx.doi.org/10.1016/j.isprsjprs.2013.09.001:

Simon Plank, John Singer, Kurosch Thuro: Assessment of number and distribution of persistent scatterers prior to radar acquisition using open access land cover and topographical data. ISPRS Journal of Photogrammetry and Remote Sensing 85 (2013) 132-147.

\title{
Assessment of number and distribution of persistent scatterers prior to radar acquisition using open access land cover and topographical data
}

\author{
Simon Plank ${ }^{1 *}$, John Singer ${ }^{2}$ and Kurosch Thuro ${ }^{3}$ \\ ${ }^{1}$ German Remote Sensing Data Center, German Aerospace Center (DLR), Oberpfaffenhofen, Münchner Straße 20, \\ 82234 Weßling, Germany \\ ${ }^{2}$ Chair of Engineering Geology, Swiss Federal Institute of Technology, ETH Zürich, Sonnegstrasse 5, 8092 Zürich, \\ Switzerland \\ ${ }^{3}$ Chair for Engineering Geology, Technische Universität München (TUM), Arcisstr. 21, 80333 Munich, Germany \\ * Corresponding author. Tel.: +49 815328 3460, fax: +49 8153281445 \\ E-mail addresses: simon.plank@dlr.de, john.singer@erdw.ethz.ch,thuro@tum.de
}

\begin{abstract}
Persistent scatterer synthetic aperture radar interferometry (PSI) is a powerful remote sensing technique to detect and measure deformation of the Earth's crust - such as subsidence and landslides - with an accuracy of a few millimeters. Deformation is measured at specific points in a radar image called persistent scatterers (PS), which are characterized by long-term constant backscattering properties (high coherence) of the radar signal. Reliable PSI processing requires a stack of 15 to 50 SAR images and more, and processing is time-consuming (computational costs) and expensive (referring to both, costs for the SAR data and labor costs). Previous research for PS assessment used already acquired SAR data. This paper presents two new methods for predicting PS prior to the radar recording of the area of interest using freely available or low-cost land cover data, topographical maps and OpenStreetMap data. In the procedure, the distance between the assessed PS is calculated and classified regarding to the applicability for PSI processing. Additionally, the dispersion of the assessed PS within the site is analyzed. The results of the two assessment methods are validated using data of real PSI processing. Here, we show that the developed PS assessment techniques are fast and reliable tools to test the spatial applicability of PSI.
\end{abstract}

\section{Keywords}

Radar; SAR; Prediction; GIS; Persistent Scatterer Processing

\section{Introduction}

In recent years, persistent scatterer synthetic aperture radar interferometry (PSI) has proven to be a powerful remote sensing technique to measure deformation of the Earth's crust - such as subsidence (e.g. Ketelaar, 2009; Tosi et al., 2009; Hung et al., 2011; Heleno et al., 2011; Ng et al., 2011; Cigna et al., 2012), landslides (e.g. Colesanti et al., 2003a; Metternicht et al., 2005; Lauknes et al., 2010; Bovenga et al., 2012), soil consolidation (e.g. Tosi et al., 2012), volcanoes (Cong e al., 2010; Hooper et al., 2012) and tectonic deformation (e.g. Massironi et al., 2009; Vilardo et al., 2009) - with an accuracy of a few millimeters. The PSI technique is described in detail in Ferretti et al. (2000b; 2001) and Kampes (2006). However, a high quality PSI processing is only possible with a stack containing at least 15 to 50 SAR images, depending on the site's land cover (Ferretti et al., 2000a; Colesanti et al., 2003a; Hanssen, 2005; Crosetto et al., 2010). This high amount of SAR images is a very critical cost factor and processing is time 
Please note that this manuscript has been published in ISPRS Journal of Photogrammetry and Remote Sensing http://dx.doi.org/10.1016/j.isprsjprs.2013.09.001:

Simon Plank, John Singer, Kurosch Thuro: Assessment of number and distribution of persistent scatterers prior to radar acquisition using open access land cover and topographical data. ISPRS Journal of Photogrammetry and Remote Sensing 85 (2013) 132-147.

consuming. Successful PSI processing requires a minimum PS density of 3 to 4 PS per $\mathrm{km}^{2}$ to be able to reconstruct and compensate the atmospheric phase screen (APS), which is caused by atmospheric heterogeneity between each SAR acquisition (Colesanti et al., 2003b). The distance between neighboring PS should not exceed a certain distance of $700 \mathrm{~m}$ (Adam, 2011) to 1,000 m (Adam et al., 2011) or 2,000 m (Zebker et al., 2007). PSI processing constructs a network between the PS. Therefore, combination of all PS into the network is a very critical issue.

Until now it is difficult to assess the number of PS targets and their distribution prior to the radar recording of the site and processing of several SAR images (Colesanti et al., 2003b; Colesanti and Wasowski, 2006; Cascini et al. 2009). This is especially true for both natural environments, such as volcanoes, forests and densely vegetated areas, marshes, lagoons, tidal-flats, and for rural areas, as in urban areas there usually is a high number of PS targets. The physical principles of PS targets in urban area have been analyzed by Ferretti et al. (2005) and Perissin et al. (2006). Here, we present two new methods for predicting possible persistent scatterers (PS) densities and distributions prior to the acquisition of the SAR images of the site. These methods can be applied in urban, rural and natural areas. The goal of this scatterer assessment is to determine, whether the scatterer density of the area of interest (AOI) is high enough for PSI processing or the scatterer density has to be artificially increased (e.g. by corner reflectors; Xia, 2008; Strozzi et al., 2009; Cong et al., 2010; Fan et al., 2010) - prior to the costly data acquisition.

This paper is divided into two parts. The first describes the PS assessment method using freely available land cover data, such as GlobCover and CORINE. This method calculates the PS density of each single land cover class. The development of this method for PS assessment was done empirically in a geographical information system (GIS) by comparing the distribution of real PS targets (results of PSI processing) of several sites with land cover data. An additional site was used for the validation of the land cover based PS assessment method.

The second method uses freely available or low-cost topographical maps (TM) and OpenStreetMap (OSM) data to assess the number of PS at a certain site. Additionally, this method enables the calculation of the distance between the assessed PS, its classification regarding to the usability for PSI processing and the analysis of the assessed PS's dispersion within the site.

To guarantee a wide usability of these methods, test areas with different types of land cover and of different climate were chosen (Fig. 1). For these sites various types of TM of different scales were available.

The results of the second PS assessment method were validated using real PS datasets. This validation enabled for each map scale the calculation of the probability for an assessed PS being a real PS. These probability values should be used at new sites for which SAR data is not yet available. The procedures are intended for a first step evaluation (pre-processing) whether the PSI technique can be applied for monitoring a certain site. In the last section (5) of the paper, a decision diagram shows the applicability of the two PS assessment methods.

\section{Reference synthetic aperture radar data}

The two PS assessment procedures, described in the sections 3 and 4 were developed using 17 PS datasets of 13 sites (Fig. 1, Tab. 1). For the Cairo, Egypt site the results of three PS detection methods processed by using ENVISAT ASAR data were used: Signal to clutter ratio (SCR), thresholding on the amplitude dispersion $\left(D_{a}\right)$ and the combination of both methods (Kampes, 2006). For the Budapest, Hungary site and the Aschau am Inn, Germany site TerraSAR-X StripMap mode data were used. The PS targets of the $100 \mathrm{~km}$ x $100 \mathrm{~km}$ large sites Bavaria, Germany, North Germany and Netherlands were processed by using ERS SAR images. The further sites are located in northwest Italy. The Aosta Valley site consists of two Radarsat-1 footprints. For both of the footprints data from ascending and from descending orbit were available. The Piedmont area consists of five sites which were all recorded by Radarsat-1: Ivrea, Omegna, Varallo, Domodossola and Novara. For the 9 sites in the Aosta Valley and in Piedmont additionally to PS targets also distributed scatterers (DS) were available. The SqueeSAR ${ }^{\mathrm{TM}}$ approach uses not only PS targets, but also DS, which correspond to neighboring pixels sharing similar reflectivity values. DS are usually found at debris areas, non-cultivated land with short vegetation or desert areas. For a detailed description of SqueeSAR ${ }^{\mathrm{TM}}$ the reader is referred to Ferretti et al. (2011). 
Please note that this manuscript has been published in ISPRS Journal of Photogrammetry and Remote Sensing http://dx.doi.org/10.1016/j.isprsjprs.2013.09.001:

Simon Plank, John Singer, Kurosch Thuro: Assessment of number and distribution of persistent scatterers prior to radar acquisition using open access land cover and topographical data. ISPRS Journal of Photogrammetry and Remote Sensing 85 (2013) 132-147.

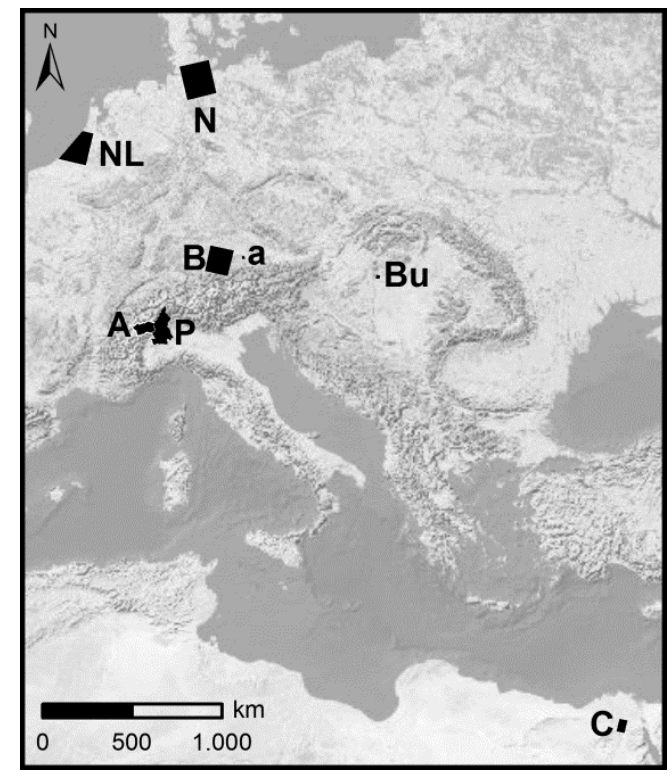

Fig. 1. Overview map of the sites Netherlands (NL), North Germany (N), Bavaria (B), Aschau am Inn (a), Aosta Valley (A), Piedmont (P) (Ivrea, Omegna, Varallo, Domodossola and Novara), Budapest (Bu) and Cairo (C). Background: (C) ESRI world shaded relief.

Tab. 1 PS datasets used

\begin{tabular}{|c|c|c|c|c|c|c|c|c|}
\hline Site & Satellite & Mode $^{1}$ & Period & $\begin{array}{l}\text { Area of } \\
\text { site }\end{array}$ & $\begin{array}{l}\text { Number } \\
\text { of images }\end{array}$ & Pass $^{2}$ & $\begin{array}{l}\text { Mid Inci- } \\
\text { dence angle }\end{array}$ & $\begin{array}{l}\text { PS identi- } \\
\text { fication }^{3}\end{array}$ \\
\hline Aschau am Inn & TerraSAR-X & SM & 2008-2011 & 10 km x 12 km & 73 & A & $41.0^{\circ}$ & $\mathrm{SCR} \& \mathrm{D}_{\mathrm{a}}$ \\
\hline Budapest & TerraSAR-X & $\mathrm{SM}$ & 2008-2010 & $13 \mathrm{~km} \mathrm{x} 14$ km & 43 & $\mathrm{D}$ & $43.4^{\circ}$ & SCR \& $D_{a}$ \\
\hline Aosta Valley & Radarsat-1 & $\mathrm{S}-3$ & 2003-2010 & 130 km x 75 km & $102(\mathrm{~A})$ & A \& D & $33.7^{\circ}(\mathrm{A})$ & $\mathrm{D}_{\mathrm{a}}$ \\
\hline (East \& West) & & & & & 94 (D) & & $33.2^{\circ}(\mathrm{D})$ & \\
\hline Ivrea & Radarsat-1 & $\mathrm{S}-3$ & 2003-2009 & $50 \mathrm{~km}$ x $60 \mathrm{~km}$ & 91 & A & $35.6^{\circ}$ & $\mathrm{D}_{\mathrm{a}}$ \\
\hline Omegna & Radarsat-1 & $\mathrm{S}-3$ & 2003-2009 & 30 km x 93 km & 86 & A & $32.6^{\circ}$ & $\mathrm{D}_{\mathrm{a}}$ \\
\hline Varallo & Radarsat-1 & $\mathrm{S}-3$ & 2003-2009 & 35 km x 80 km & 92 & A & $36.2^{\circ}$ & $\mathrm{D}_{\mathrm{a}}$ \\
\hline Domodossola & Radarsat-1 & S-3 & 2003-2009 & 60 km x 90 km & 77 & $\mathrm{D}$ & $35.3^{\circ}$ & $\mathrm{D}_{\mathrm{a}}$ \\
\hline Novara & Radarsat-1 & S-3 & 2003-2009 & 70 km x 55 km & 77 & $\mathrm{D}$ & $34.8^{\circ}$ & $\mathrm{D}_{\mathrm{a}}$ \\
\hline \multirow[t]{2}{*}{ Cairo } & ENVISAT & IM & 2003-2009 & 70 km x 45 km & 38 & $\mathrm{D}$ & $23.0^{\circ}$ (IS2) & $\mathrm{SCR}, \mathrm{D}_{\mathrm{a}}$ \\
\hline & & & & & & & & SCR \& $D_{a}$ \\
\hline Bavaria & ERS-1 \& 2 & - & 1992-2002 & 100 km x 100 km & 81 & $\mathrm{D}$ & $23.0^{\circ}$ & SCR \\
\hline Netherlands & ERS-1 \& 2 & - & 1992-2001 & 80 km x 100 km & 75 & $\mathrm{D}$ & $23.0^{\circ}$ & $\mathrm{D}_{\mathrm{a}}$ \& Coh. \\
\hline North Germany & ERS-1 \& 2 & - & 1993-2000 & 100 km x 100 km & 34 & $\mathrm{~A}$ & $23.0^{\circ}$ & SCR \\
\hline
\end{tabular}

${ }^{1}$ Mode: SM = StripMap (TerraSAR-X), S = Standard (Radarsat-1), IM = Image (ENVISAT ASAR) 
Please note that this manuscript has been published in ISPRS Journal of Photogrammetry and Remote Sensing http://dx.doi.org/10.1016/j.isprsjprs.2013.09.001:

Simon Plank, John Singer, Kurosch Thuro: Assessment of number and distribution of persistent scatterers prior to radar acquisition using open access land cover and topographical data. ISPRS Journal of Photogrammetry and Remote Sensing 85 (2013) 132-147.

${ }^{2}$ Pass: $\mathrm{A}$ = Ascending; $\mathrm{D}=$ Descending

${ }^{3}$ PS identification method: $\mathrm{D}_{\mathrm{a}}=$ Amplitude dispersion; SCR $=$ Signal to clutter ratio; SCR \& $\mathrm{D}_{\mathrm{a}}=$ Combination of both methods; $D_{a} \&$ Coh. $=$ First $D_{a}$, then refinement with coherence; However, the terms for the PS identification method are a very strong simplification. For each site (except of the Cairo site) the final results of the entire PSI processing chain were used. That means all datasets were processed using different PSI processing chains with different processing parameters.

\section{PS assessment based on land cover data}

\subsection{Freely available land cover data}

The first method uses freely available land cover data to assess the PS density prior to the radar recording of the area of interest. We used two types of land cover datasets with different ground coverage and spatial resolution. The first one is the GlobCover 2009 land cover dataset, which is characterized by a global coverage and a spatial resolution of $300 \mathrm{~m}$. This dataset was derived by the classification of MERIS (Medium Resolution Imaging Spectrometer) data. This sensor flew on board of the ENVISAT satellite. The dataset distinguishes 22 land cover classes. More information about this land cover data is available at: http://ionia1.esrin.esa.int/.

The second land cover dataset used in the PS density assessment method is the year 2006 version of Coordination of Information on the Environment (CORINE) land cover data, which has a spatial resolution of $100 \mathrm{~m}$. Due to its limited coverage this land cover dataset was used for the twelve European sites. CORINE land cover is based on satellite data (scale 1:100,000). 44 land cover classes are distinguished. CORINE 2006 is available at: http://www.eea.europa.eu.

\subsection{Land cover PS assessment: method}

This PS assessment method is based on an empirical approach. Datasets of geocoded processed PS from sites of different climate zones and geographical regions (see section 2) were compared with the land cover datasets described in section 3.1. The goal of this method is to assess the PS density of a certain site prior to its radar recording. Therefore, for each single land cover class the number of PS targets $N$ lying inside the land cover class is calculated. This was implemented by counting the number of geocoded PS $N_{k}$ (of the reference SAR data) for each single subarea $k$ of each land cover class and then summing up the results $\left(N=\sum N_{k}\right)$. Then, the entire area of the class (within the site) $A$ was calculated. Next, the PS density $p$ (PS targets per km²) was derived (Eq. (1)).

$$
p=\frac{N}{A}
$$

The procedure described above was implemented in a geographical information system (GIS) and executed for each site and land cover dataset.

When comparing the single results of the different sites, we identified strong variations of the absolute PS density within each land cover class. The reason for this is that the sites were recorded by different SAR sensors working with different wavelengths, different imaging modes, etc., and the PS processing was applied by using different PSI algorithms. To enable comparison of the datasets from different sites, we developed the so-called relative PS density. The relative PS density was derived by normalizing the absolute PS densities by a reference class, which was set equal to 1 .

The idea of the relative PS density method is to use the graphs described in section 3.3 to assess the absolute PS density of all land cover classes within the site, prior to its radar recording. Precondition for the relative PS density method is an assessment of absolute PS density in the reference class. As PSI has very often been successfully applied in urban areas (Colesanti et al., 2003a; Refice et al., 2005; Colesanti and Wasowski, 2006), there already exists a lot of information about the absolute PS density values in urban area for different SAR sensors and PSI 
Please note that this manuscript has been published in ISPRS Journal of Photogrammetry and Remote Sensing http://dx.doi.org/10.1016/j.isprsjprs.2013.09.001:

Simon Plank, John Singer, Kurosch Thuro: Assessment of number and distribution of persistent scatterers prior to radar acquisition using open access land cover and topographical data. ISPRS Journal of Photogrammetry and Remote Sensing 85 (2013) 132-147.

processing algorithms. Therefore, we chose the class 'urban area' as reference class for the relative PS density method.

We point out, that the class 'urban area' is only required at the sites used for the calibration of this PS assessment method. However, for the application of this method urban area within the area of interest is not mandatory. The great advantage of the land cover based PS assessment method is the possibility to assess the PS density also for land cover classes which are not represented in the reference site from which the value of the reference class urban area is taken.

\subsection{Land cover PS assessment: calibration}

This section describes the calibration of the land cover PS method. The GlobCover dataset was used for PS datasets of the sites Cairo (3 PS datasets, see section 2), Budapest, Bavaria, North Germany, Netherlands, Omegna, Varallo, Domodossola, Novara and Aosta Valley West (ascending and descending). The sites Aosta Valley East and Aschau am Inn could not be considered for the GlobCover dataset, as in both sites the area of the reference class urban area is very low (ca. $3 \mathrm{~km}^{2}$, which is less than $0.25 \%$ of the entire site area). At such small areas very small changes of the number of PS targets result in large variations of the PS density, which could distort the results of the relative PS density method. Consequently, these areas are not suited for the calibration of the relative PS density graphs. But for a later application of the method developed in this paper urban area within the AOI is not required.

Due to the higher spatial resolution of the CORINE dataset there is sufficiently large percentage of urban area within each site. Therefore, all European sites were used - except of the Ivrea site which was excluded from the calibration of both GlobCover and CORINE dataset and used for validation of the results (see section 3.4).

At most land cover classes the comparison of the relative PS density of all sites showed a very low variation. However, some land cover classes show strong variations for the different sites. At these land cover classes the influence of the factors mentioned in the following are much stronger than the majority of the land cover classes. These factors are the topographic relief and the climate of the site, the PS detection method used for PSI processing and the wavelength of the SAR sensor. We considered these stronger influences on the appropriate land cover classes by generating sub classes for them.

Areas of arid climate, which are characterized by low annual precipitation and the resulting sparse vegetation, are much better suited to form PS than humid areas, as the latter are characterized by much higher vegetation density. Consequently, we divided the sites into the areas of humid (precipitation > evaporation all year; European sites) and arid (precipitation < evaporation all year; Cairo site) climate. For instance, the annual precipitation of the Aosta Valley site (ca. $1863 \mathrm{~mm} / \mathrm{a}$ ) is much higher than that of the arid Cairo site (ca. $29 \mathrm{~mm} / \mathrm{a}$ ). The climate of the site can be determined using for example the updated world map of the Köppen-Geiger climate classification developed by Peel et al. (2007), which is freely available at http://www.hydrol-earth-syst-sci.net/11/1633/2007/hess-11-16332007-supplement.zip).

As high mountains (e.g. the Alps) are characterized by (1) strong geometrical distortions, such as the layover and shadowing effect (Lillesand and Kiefer, 2000; Barbieri and Lichtenegger, 2005; Colesanti and Wasowski, 2006; Plank et al., 2012), (2) extensive coverage of snow and ice in winter and spring, (3) very high annual precipitation (e.g. Aosta Valley: $1863 \mathrm{~mm} / \mathrm{a}$ ), PSI applications in these areas are very complicated. Therefore, we defined subclasses to divide the sites in areas of high mountains (in our case the Alpine sites of the Aosta Valley and Piedmont) and flat and hilly terrain (all remaining sites) delimited by a $20^{\circ}$ threshold for the mean slope. This threshold was derived by investigating the mean of slope of the corresponding land cover classes (bare areas, sparse vegetation, rocks, see also below) using a Shuttle Radar Topography Mission (SRTM) C-band DEM. We identified two peaks in the frequency distribution. The Alpine areas showed values of greater than $26^{\circ}$ for the mean slope inclination, while all other sites are located at flat (with inclination of slope $<2^{\circ}$ ) and hilly terrain.

Whether an object of a certain size is able to function as a PS target depends on the spatial resolution of the SAR sensor used. At high spatial resolution SAR sensors such as the X-band missions TerraSAR-X and COSMO-SkyMed 
Please note that this manuscript has been published in ISPRS Journal of Photogrammetry and Remote Sensing http://dx.doi.org/10.1016/j.isprsjprs.2013.09.001:

Simon Plank, John Singer, Kurosch Thuro: Assessment of number and distribution of persistent scatterers prior to radar acquisition using open access land cover and topographical data. ISPRS Journal of Photogrammetry and Remote Sensing 85 (2013) 132-147.

(esp. in StripMap mode or higher spatial resolution), smaller objects of decimeter size could work as PS targets, while SAR Sensors working at C-band (lower spatial resolution) (in our work: Radarsat-1 Standard mode, ERS and ENVISAT) larger objects of meter size are needed to form PS targets. To take the different behavior of X- and Cband SAR sensors into account, we defined two subclasses. As described below, only the class 'road \& railroad' is affected by the SAR sensor's wavelength.

When comparing the results of different PS detection methods (SCR and $\mathrm{D}_{\mathrm{a}}$ ) at natural areas free of vegetation, we identified high variation of the relative PS density. The SCR method detects only pixels whose intensity values are higher than that of their spatial neighborhood. In contrast to this, the $\mathrm{D}_{\mathrm{a}}$ method investigates the relationship of the temporal standard deviation and the temporal mean of the amplitude of a certain pixel in a stack of SAR images. At the desert areas of the Cairo site we identified strong differences when comparing the relative PS density obtained by the SCR and the $D_{a}$ PS detection method. The rocky and stony desert of the Cairo site shows a very low $D_{a}$, which is an indicator for low phase dispersion and therefore a high probability to form a PS. However, contrary to urban areas, the rocky desert does not show very high intensity values in a SAR image. Consequently, at rocky and stony desert areas the SCR method detects a lower number of possible PS than the $\mathrm{D}_{\mathrm{a}}$ method. Therefore, we defined subclasses to consider the differences of the PS detection method at this land cover type. Prerequisite for a good applicability of both PS detection methods SCR and $D_{a}$ is a high signal to noise ratio (SNR) of the SAR data.

In general, especially land cover classes characterized by a low PS(DS) density, which are mainly densely vegetated land cover classes, show a comparatively high variation of the relative PS(DS) density values when comparing the results of all sites (Figs. 2 and 3). However, the variations within these land cover classes are low enough to enable useful results for the PS assessment procedure (see sections 3.4 and 3.5).

\subsubsection{GlobCover}

The Figs. 2a and $b$ show the average mean of the relative PS density of the GlobCover dataset for PS and DS\&PS (distributed scatterers and PS targets), respectively. As mentioned in section 3.1 the GlobCover dataset has a global coverage, but a very general thematic classification (only 22 classes). This very low number of classes does not consider the climatic differences of the sites. For instance, the GlobCover class 'bare areas' contains the desert areas of the Cairo site and bare rock areas of the Alpine sites (Aosta Valley and Piedmont) in the same land cover class. Both regions are characterized by a very different climate. As mentioned above, the class 'bare areas' in the Alpine sites is not as suitable for PSI processing as the same land cover class at the Cairo site characterized by arid climate. Therefore, we applied the aforementioned climate based sub-classification of the GlobCover class 'bare areas'. The class was divided into the subclasses 'bare areas, arid' representing the Cairo site and 'bare areas, humid' for all European sites.

By investigating the single values of the relative PS density, we recognized at the land cover classes 'sparse vegetation' and 'bare areas' large differences between the Alpine sites (Piedmont and Aosta Valley) and the other European humid climate sites. At the Alpine sites both land cover classes are restricted to high mountainous areas with mean slope inclination greater than $26^{\circ}$. As explained above, PSI application in these areas is very difficult. Contrary to this, at the other sites these two land cover classes are located at flat (with inclination of slope $<2^{\circ}$ ) and hilly terrain. Consequently, we applied the aforementioned threshold of $20^{\circ}$ of the mean slope inclination and defined two sub-classes for each land cover class: '... in flat and hilly terrain' (mean slope inclination $<20^{\circ}$ ) and '... in high mountains' (mean slope inclination $>20^{\circ}$ ).

The 'bare areas' of the Cairo site show very different values for the three different PS detection methods (described in section 2; Kampes, 2006). The relative PS density of the method thresholding on the amplitude dispersion is more than twice as high as for the thresholding on the SCR method (this effect is explained in 3.3). The combination of both methods is between both values. To take this significant difference of the three PS detection methods for 'bare areas' into account, we defined three subcategories depending on the PS detection technique. 
Please note that this manuscript has been published in ISPRS Journal of Photogrammetry and Remote Sensing http://dx.doi.org/10.1016/j.isprsjprs.2013.09.001:

Simon Plank, John Singer, Kurosch Thuro: Assessment of number and distribution of persistent scatterers prior to radar acquisition using open access land cover and topographical data. ISPRS Journal of Photogrammetry and Remote Sensing 85 (2013) 132-147.

After considering all the effects described above, the relative PS density values show a good conformity within all the different land cover classes.

a)

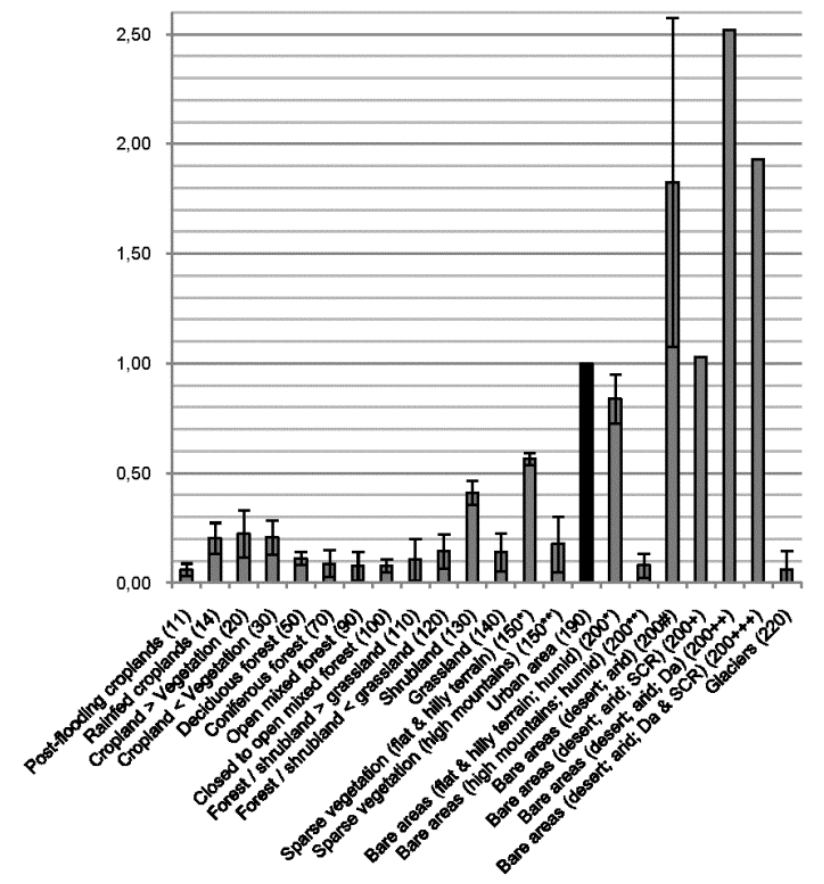

b)

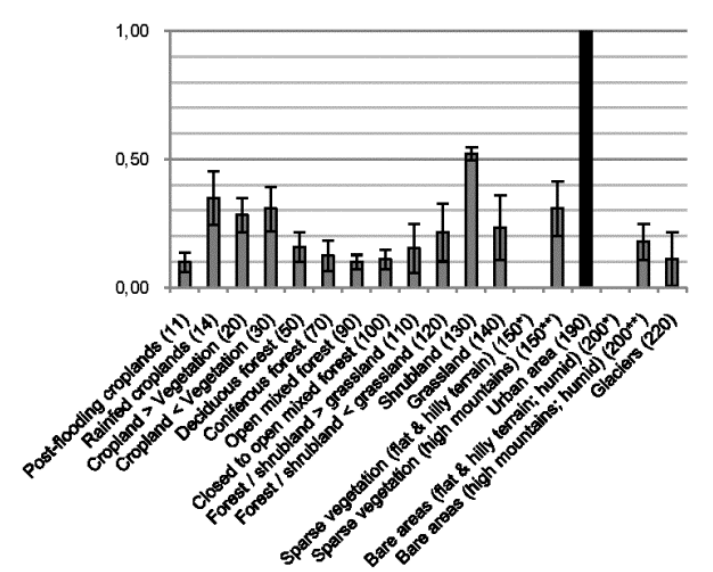

Fig. 2. GlobCover 2009 arithmetic mean of the relative PS density based on 13 datasets (a) and the relative DS\&PS density based on 6 datasets (data only available for Aosta Valley West and the Piedmont sites) (b). The numbers show the ID of the GlobCover land cover classification. The reference class urban area is marked black. The small bars show the standard deviation values. 
Please note that this manuscript has been published in ISPRS Journal of Photogrammetry and Remote Sensing http://dx.doi.org/10.1016/j.isprsjprs.2013.09.001:

Simon Plank, John Singer, Kurosch Thuro: Assessment of number and distribution of persistent scatterers prior to radar acquisition using open access land cover and topographical data. ISPRS Journal of Photogrammetry and Remote Sensing 85 (2013) 132-147.

\subsubsection{CORINE}

The Figs. 3a and b show the relative PS density values for the CORINE dataset for PS and DS\&PS (distributed scatterers and PS targets), respectively. The land cover classes 'continuous urban area' (densely build-up area), 'industrial' and 'port areas' show high variability of the relative PS(DS) density, however as the values are near or above the reference class 'discontinuous urban area', enough PS targets should always be found at these areas.

When considering the single values of the class 'road \& railroad', we identified that the relative PS density of the Xband sites (Tab. 1) is as twice as high as for the other sites. As mentioned above, due to its smaller wavelength, at Xband smaller objects of decimeter size on the ground could work as PS target (e.g. road signs, overhead line masts, etc.). Contrary to this, C-band requires larger objects of meter size for working as PS target. As this different behavior of X- and C-band data is very high for the CORINE class 'road \& railroad', we applied the aforementioned sub-classification 'road \& railroad (for X-band)' and 'road \& railroad (for C-band)' for this land cover class. The influence of the wavelength on the relative PS density is negligibly low at the other land cover classes.

The land cover classes 'mineral extraction', 'dump sites' and 'construction sites' show very large variations of the relative PS(DS) density. As these classes show strong changes over a short time period, the time lag between the acquisition date of the multispectral satellite data used for the classification of the CORINE land cover data and the acquisition date of the SAR data is very important. The larger this time lag becomes, the stronger the uncertainty of the relative PS density gets. This very high temporal variability makes the application of PSI very difficult there.

The single values of the class 'sands' showed very different values depending on the type of geographic location. The widely sandy North Sea beaches of the Netherland and North Germany sites contain no rocks and very rarely buildings. Therefore, they show a very low PS density. As opposed to this, in the Piedmont sites the class 'sands' is located at riverbanks containing much more rocks and buildings in the neighborhood, which can work as PS targets. Consequently, we divided the class 'sands' into the two subcategories 'sands (seashore)' and 'sands (riverbank)'. But it is important to notice, that the term 'seashore' represents widely sandy beaches with no rocks and only a few buildings, as e.g. at the Dutch and German North Sea coast. However, if the site is characterized by a coast containing significantly more rocks and therefore more potential PS targets, the relative PS density value of the class 'sands (riverbank)' should be used. By using freely available optical data (e.g. Landsat and ASTER) or Google Earth ${ }^{\mathrm{TM}}$, one is able to get an overview of the coast characteristic.

As already mentioned for the GlobCover land cover dataset, also for the classes 'sparse vegetation' and 'bare rocks' of the CORINE land cover we applied the aforementioned sub-classes based on the $20^{\circ}$ inclination of slope threshold in each case. As none of the sites used for the calibration represents the sub-class 'bare rocks in flat \& hilly terrain', only the class 'bare rocks in high mountains' is shown in the Figs. 3a and b. 
Please note that this manuscript has been published in ISPRS Journal of Photogrammetry and Remote Sensing http://dx.doi.org/10.1016/j.isprsjprs.2013.09.001:

Simon Plank, John Singer, Kurosch Thuro: Assessment of number and distribution of persistent scatterers prior to radar acquisition using open access land cover and topographical data. ISPRS Journal of Photogrammetry and Remote Sensing 85 (2013) 132-147.

a)

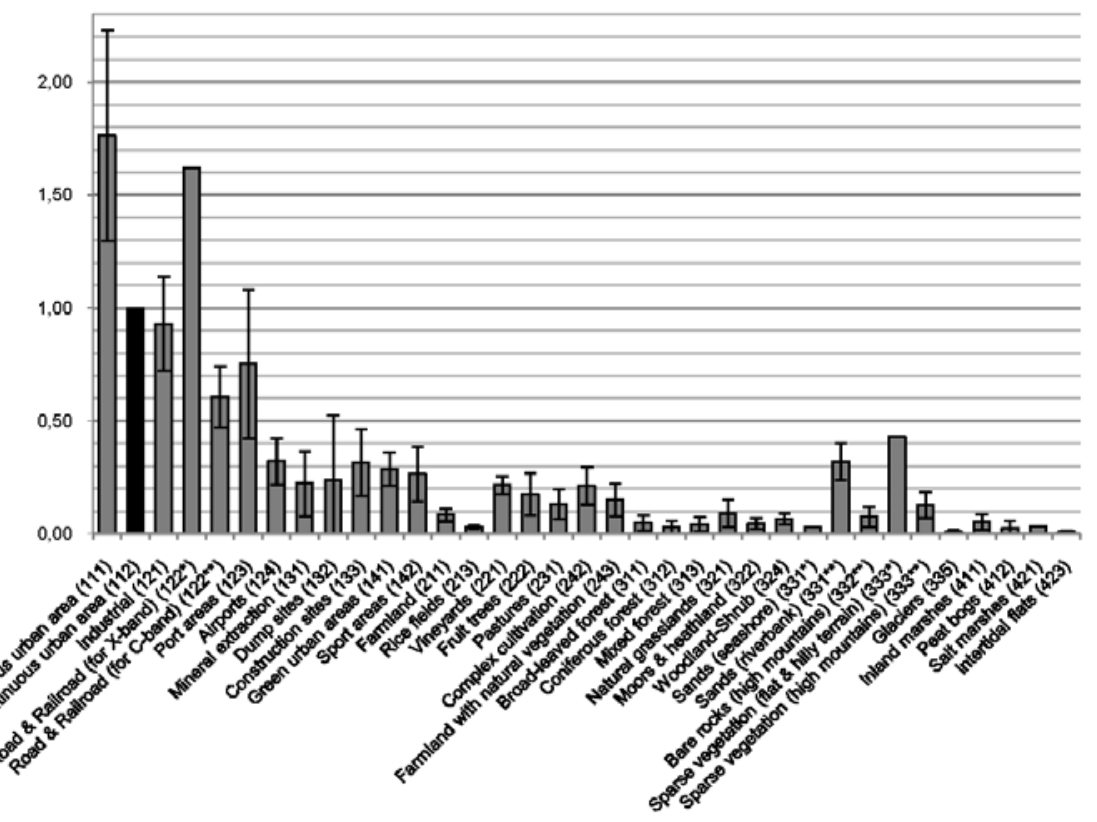

b)

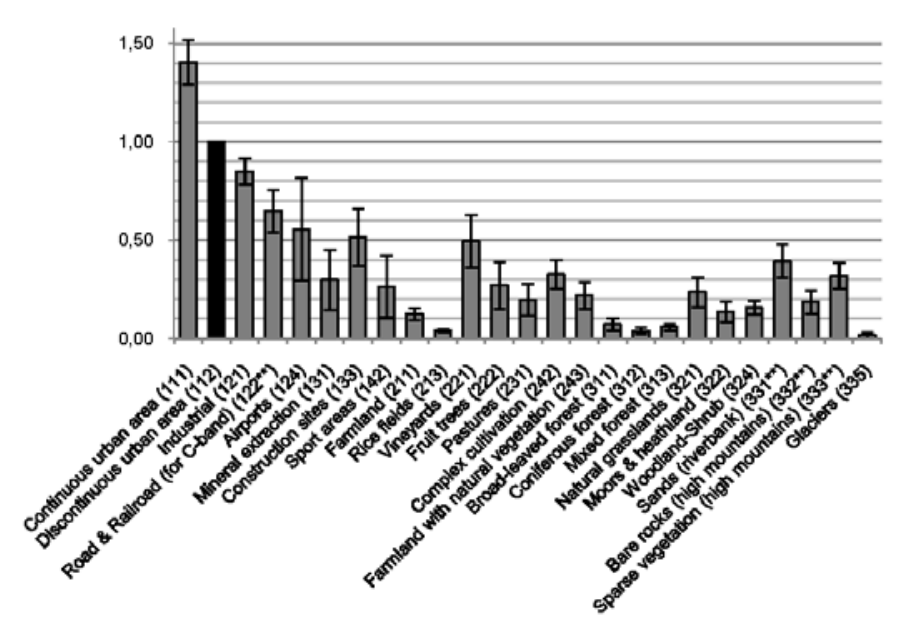

Fig. 3. CORINE 2006 arithmetic mean of the relative PS density based on 13 datasets (a) and the relative DS\&PS density based on 8 datasets (data only available for Aosta Valley and the Piedmont sites) (b). The numbers show the ID of the CORINE land cover classification. The reference class discontinuous urban area is marked black. The small bars show the standard deviation values. 
Please note that this manuscript has been published in ISPRS Journal of Photogrammetry and Remote Sensing http://dx.doi.org/10.1016/j.isprsjprs.2013.09.001:

Simon Plank, John Singer, Kurosch Thuro: Assessment of number and distribution of persistent scatterers prior to radar acquisition using open access land cover and topographical data. ISPRS Journal of Photogrammetry and Remote Sensing 85 (2013) 132-147.

\subsection{Application and validation of the land cover PS assessment method}

As a case study this paper shows the PS density assessment using the relative PS density graph of the CORINE 2006 land cover dataset. The method was applied at the Ivrea site, which was not included in the calibration procedure (cf. section 3.3), by multiplying the relative PS density of each single CORINE land cover class of Fig. 3a with the absolute value of the reference class urban area of the Omegna site. The sites Ivrea and Omegna were both recorded by Radarsat- 1 and processed by the same or comparable PS detection and processing algorithms. Therefore, both sites show similar values for the PS density in the reference class urban area. As both sites cover different geographical areas and belong to different tracks, the value of the reference class from the Omegna site can be used for the validation of the land cover PS assessment at the Ivrea site. Both sites were also recorded at similar incidence angles (cf. Tab. 1), which is not mandatory for the application of the land cover based PS assessment method. However, strong differences in the acquisition geometry change the number of PS at the reference class.

The Figs. $4 \mathrm{a}$ and $\mathrm{b}$ show the processed (results of real SAR data) and the assessed PS density of the Ivrea site using the CORINE land cover relative PS density graph (Fig. 3a). The visual comparison shows a very good match of processed and assessed PS density. The maximum value of the assessed PS density (434 PS/ $\mathrm{km}^{2}$ ) reaches ca. $97.5 \%$ of the processed one (445 PS/ $\mathrm{km}^{2}$ ). In both figures the clusters of high PS density (cities in the N, SE and SW) can be clearly recognized. Also the very low PS density of the southeast part of the site (CORINE class rice fields) match very well in both maps.

Generally, the assessment is slightly smoothed as the assessed PS density is equal within the entire land cover class. As opposed to this, the processed PS density shows more clustering as the PS targets are mainly concentrated to buildings. The areas of underestimation are mainly restricted to the urban areas (Fig. 4c). As the assessment recognizes these urban areas as areas with high PS density, this underestimation does not matter very much. In the northwest of the Ivrea site one can recognize a small area of strong underestimation. This area is covered by sparse vegetation characterized by a much higher PS density than the mean of this class from the sites used for the calibration of the relative PS density. A visual examination of this area in Google Earth ${ }^{\mathrm{TM}}$ showed a very high density of rocks, which can function as PS targets.

The frequency distribution of the difference between the assessed and the processed PS density (Fig. 5c) shows a strong concentration at the interval of $\pm 20 \mathrm{PS} / \mathrm{km}^{2}$ (63.4\% of the site's area) and confirms the visual impression of the good conformity between both PS density maps.

Additionally, the percental deviation $p_{d}$ of the assessed $p_{a}$ and processed PS density $p_{p}$ was calculated according to Eq. (2).

$$
p_{d}=\frac{p_{a}-p_{p}}{p_{p}} \cdot 100 \%
$$

Fig. 6c shows $p_{d}$ for the PS assessment based on the CORINE land cover data. As demonstrated for the absolute PS density difference (Fig. 5c), also the percental deviation of the assessed and processed PS density shows a concentration of the percentage values at the $\pm 20 \%$ interval, which represents a good match of the assessed and processed PS density.

When looking at Fig. 6c, one also recognizes two 'outliers'. The term 'NaN' (not a number) represents all pixels of the area of interest where $p_{p}$ equals to zero, i.e. there is no processed PS located within this raster cell. 'NaN' represents an overestimation the PS density for $p_{p}=12.2 \%$ of the site's area. The second 'outlier' is the interval of strong overestimation of the assessed PS density (interval $>+100 \%$ ). At a first glance, the value for the interval $>+100 \%$ is very high (30\%). However, one has to consider, that the processed (real) PS are not equally distributed within a certain land cover class, but clustered at specific locations (e.g. at single buildings or small groups of buildings which are too small to be mapped as an independent land cover class urban area). Contrary to this, the value for the assessed PS density is equally within the entire land cover class. Detailed investigations showed that this strong overestimation of the PS density is limited to areas of low processed PS density (e.g. forests and 
Please note that this manuscript has been published in ISPRS Journal of Photogrammetry and Remote Sensing http://dx.doi.org/10.1016/j.isprsjprs.2013.09.001:

Simon Plank, John Singer, Kurosch Thuro: Assessment of number and distribution of persistent scatterers prior to radar acquisition using open access land cover and topographical data. ISPRS Journal of Photogrammetry and Remote Sensing 85 (2013) 132-147.

farmland). At these low PS density land cover classes, the number of raster cells with less processed PS than the assessment for the corresponding land cover class exceeds the number of pixels which contain the clusters of processed PS (higher PS density than at the assessment). This causes an overestimation of the assessed PS density at these raster cells. However, one has to consider, that $p_{d}$ is a relative deviation. That means, if the processed PS density for a forest land cover class is e.g. $2 \mathrm{PS} / \mathrm{km}^{2}$ and the assessment results in $5 \mathrm{PS} / \mathrm{km}^{2}$, one receives a strong overestimation of $p_{d}$ equal to $150 \%$. Although there is a high relative overestimation, the absolute difference of the assessed and the processed PS density is with $3 \mathrm{PS} / \mathrm{km}^{2}$ very low and confirms a good match.

In conclusion, the comparison of the absolute assessed and processed PS density shows a very good conformity (Fig. 5c) and confirms a good applicability of the CORINE land cover data for PS assessment, prior to a SAR recording of the AOI. However, especially at land cover classes of low PS density (e.g. densely vegetated areas) one has to consider the trend for overestimation of the assessment (see relative deviation, Fig. 6c).
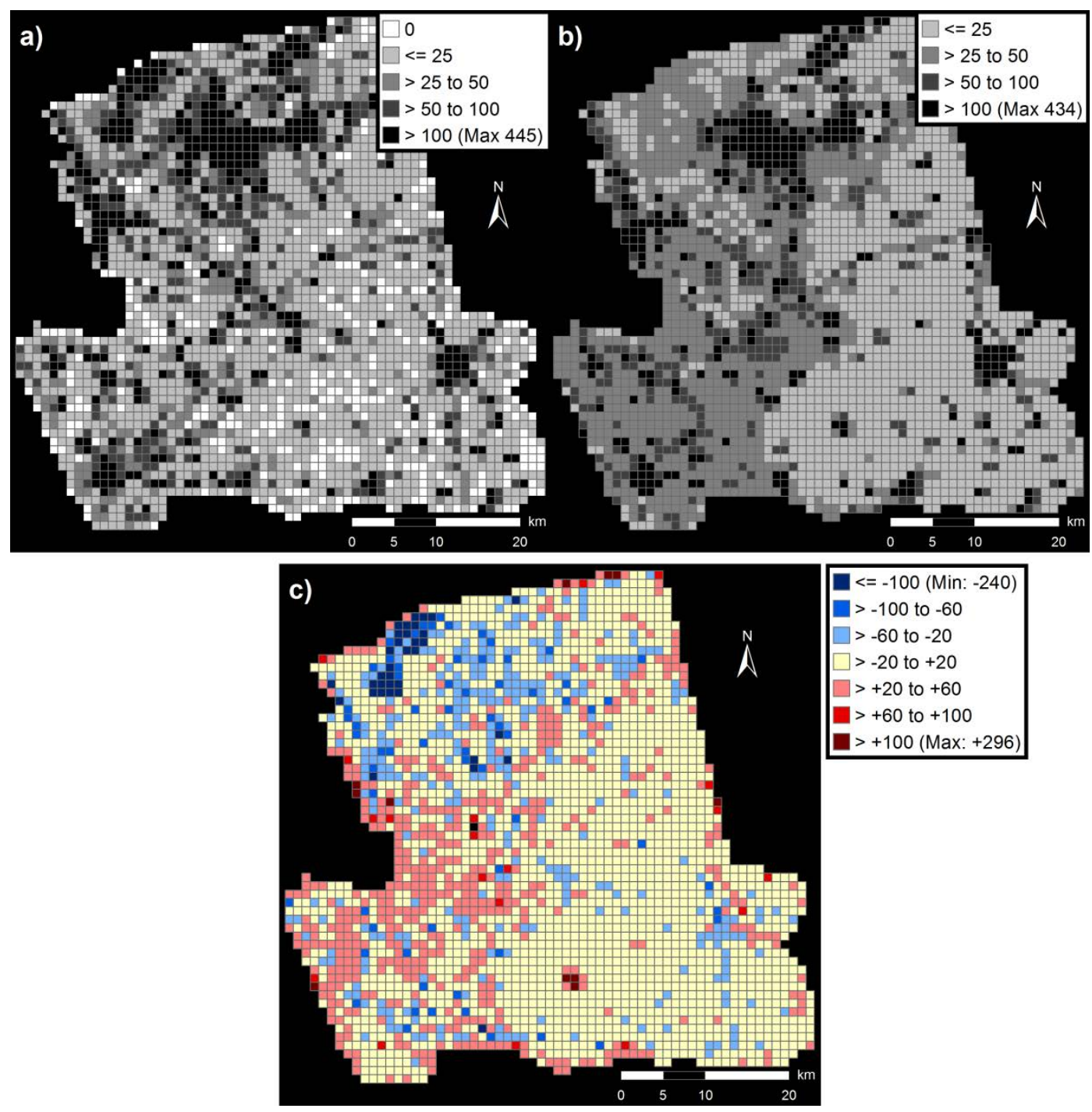

Fig. 4. Ivrea site: Processed PS density [PS/ $\left.\mathrm{km}^{2}\right]$ (a), assessed PS density [PS/km²] using the mean of the relative PS density of CORINE (b) and difference of assessed and processed PS density [PS/ $\left.\mathrm{km}^{2}\right]$ (c). Overestimation (> 0), underestimation $(<0)$. 
Please note that this manuscript has been published in ISPRS Journal of Photogrammetry and Remote Sensing http://dx.doi.org/10.1016/j.isprsjprs.2013.09.001:

Simon Plank, John Singer, Kurosch Thuro: Assessment of number and distribution of persistent scatterers prior to radar acquisition using open access land cover and topographical data. ISPRS Journal of Photogrammetry and Remote Sensing 85 (2013) 132-147.

a)

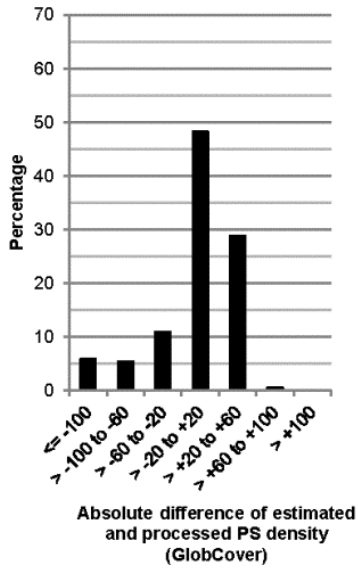

c)

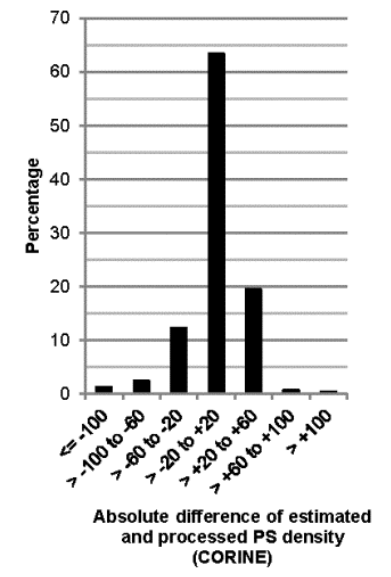

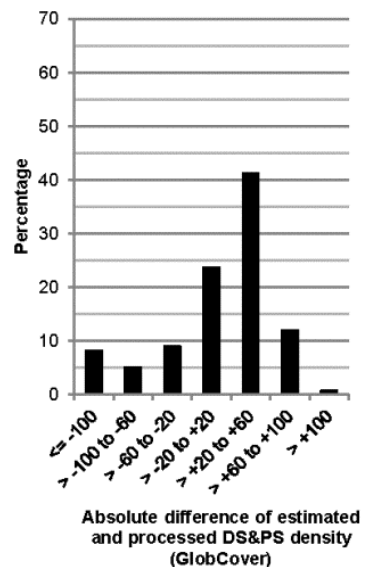

d)

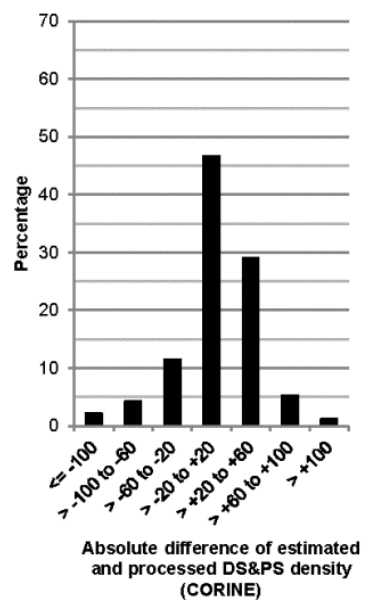

Fig. 5. Ivrea site: Percentage of difference of assessed and processed (DS\&)PS density. GlobCover 2009 PS density (a), GlobCover 2009 DS\&PS density (b), CORINE 2006 PS density (c) and CORINE 2006 DS\&PS density (d). Overestimation $(>0)$, underestimation $(<0)$. 
Please note that this manuscript has been published in ISPRS Journal of Photogrammetry and Remote Sensing http://dx.doi.org/10.1016/j.isprsjprs.2013.09.001:

Simon Plank, John Singer, Kurosch Thuro: Assessment of number and distribution of persistent scatterers prior to radar acquisition using open access land cover and topographical data. ISPRS Journal of Photogrammetry and Remote Sensing 85 (2013) 132-147.
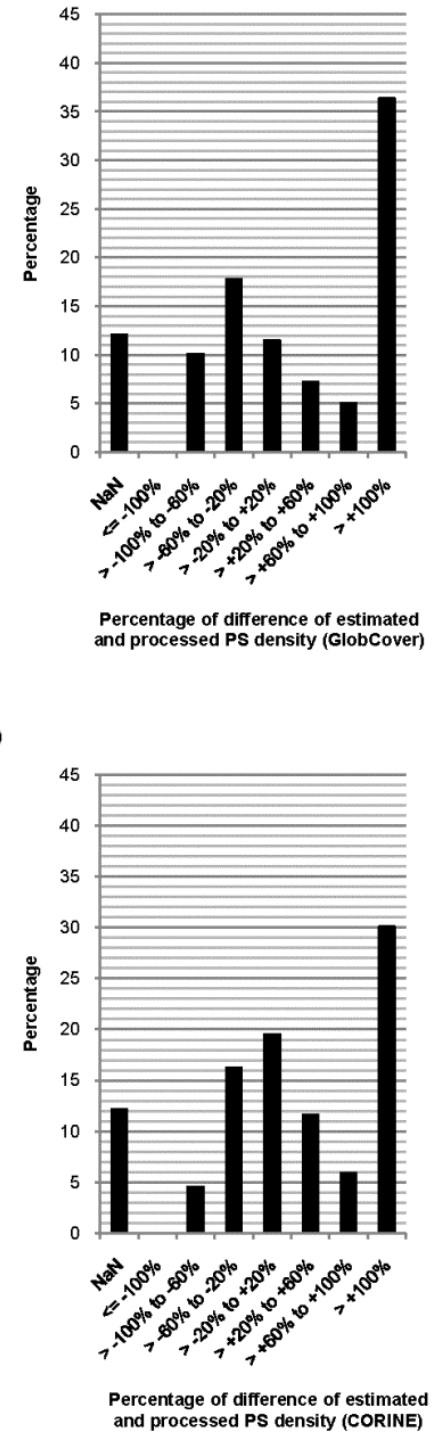
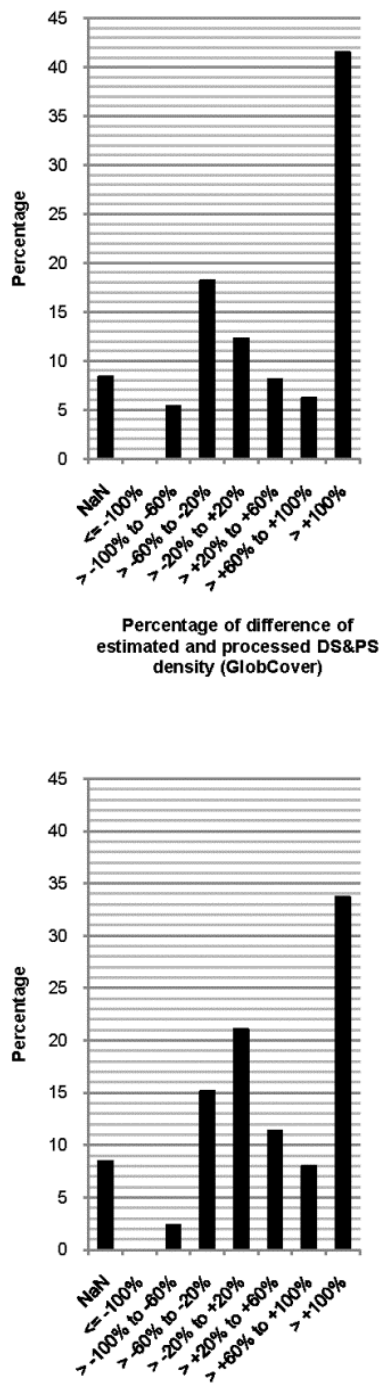

Percentage of difference of estimated and processed DS\&PS density (CORINE)

Fig. 6. Ivrea site: Relative deviation of assessed and processed PS density (see Eq. (2)). GlobCover 2009 PS density (a), GlobCover 2009 DS\&PS density (b), CORINE 2006 PS density (c) and CORINE 2006 DS\&PS density (d). Overestimation ( $>0 \%)$, underestimation $(<0 \%)$, 'NaN' = not a number (described in section 3.4). 
Please note that this manuscript has been published in ISPRS Journal of Photogrammetry and Remote Sensing http://dx.doi.org/10.1016/j.isprsjprs.2013.09.001:

Simon Plank, John Singer, Kurosch Thuro: Assessment of number and distribution of persistent scatterers prior to radar acquisition using open access land cover and topographical data. ISPRS Journal of Photogrammetry and Remote Sensing 85 (2013) 132-147.

\subsection{Conclusion of the validation}

Fig. 5 shows the percentage of difference of the assessed and processed (DS\&)PS density for all four cases. The best results (= best fit of assessed and processed PS density) was achieved using CORINE for PS assessment: Over $63 \%$ of the site's area show differences of only $\pm 20 \mathrm{PS} / \mathrm{km}^{2}$ (see above). The GlobCover dataset shows the second best result when predicting the PS density. Here, $48.3 \%$ of the site's area shows a difference of $\pm 20 \mathrm{PS} / \mathrm{km}^{2}$ between the assessed and processed PS density. Compared to the CORINE graph (for PS density) there is stronger overestimation at the GlobCover graph (for PS density). For instance, the interval +20 to $+60 \mathrm{PS} / \mathrm{km}^{2}$ increases from $19.4 \%$ for CORINE (Fig. 5c) to ca. $28.8 \%$ for GlobCover (Fig. 5a).

When comparing the Figs. 5a and 5b and the Figs. 5c and 5d, respectively, one can conclude, that the DS\&PS density assessment shows stronger overestimation than the corresponding PS assessment. When applying both GlobCover PS density assessment (Fig. 5a) and CORINE DS\&PS density assessment (Fig. 5d) one has to consider their tendency for overestimation. For both mentioned cases the percentage for overestimation (> $20 \mathrm{PS} / \mathrm{km}^{2}$ difference between assessed and processed PS(DS) density) is $29.4 \%$ or $35.6 \%$ for GlobCover PS assessment (Fig. 5a) or CORINE DS\&PS assessment (Fig. 5d), respectively.

$54 \%$ of the site's area shows an overestimation (> 20 DS\&PS $/ \mathrm{km}^{2}$ difference between assessed and processed DS\&PS density) for the GlobCover DS\&PS assessment (Fig. 5d). Therefore, GlobCover cannot be used for the assessment of absolute values of the DS\&PS density of the area of interest. Using the GlobCover land cover dataset, only the trend of the DS\&PS density distribution within the site can be assessed.

Fig. 6 shows the percental deviation $p_{d}$ of the assessed and processed PS density (Eq. 2). The results for CORINE land cover are very similar for the PS (Fig. 6c) and the DS\&PS (Fig. 6d) assessment. Both cases show a concentration at the $\pm 20 \%$ interval for $p_{d}$ and also the values for ' $\mathrm{NaN}$ ' $(12.2 \%$ and $8.5 \%)$ and for the $p_{d}$ interval $>+100 \%$ (30.0 \% and $33.7 \%$ ) are very similar for PS and DS\&PS, respectively. Contrary to CORINE, the results for GlobCover show a concentration at the $p_{d}$ interval $>-60 \%$ to $-20 \%$ (Fig. 6a and b), which indicates an underestimation of the assessed PS density relative to the processed one. When comparing the $p_{d}$ interval of strong relative overestimation ( $>+100 \%$ ), one recognizes an increase of ca. $21.1 \%$ or $23.3 \%$ for the corresponding GlobCover graph in comparison to CORINE PS or DS\&PS, respectively. Both mentioned results - higher values for the $p_{d}$ intervals $>-60 \%$ to $-20 \%$ and $>+100 \%$ for GlobCover in comparison to CORINE - are caused by the rougher spatial resolution of the former land cover data set, which makes the PS(DS) assessment more complicated.

As a résumé for the land cover based PS assessment method, one can conclude a good applicability to assess the PS density of the area of interest prior to its radar recording when using the higher spatial resolution CORINE land cover dataset. However, as mentioned in section 3.4, one has to consider the relative overestimation of the PS density at low PS density land cover classes (e.g. densely vegetated areas). At these land cover classes, the PS assessment method is able to predict the magnitude of the PS density (low absolute difference of the PS density, see Fig. 5), but it is not possible to assess the absolute number of the PS density.

Due to its higher spatial and thematic resolution the CORINE land cover is better suited for the relative PS density method than the GlobCover dataset. However, as in some areas only GlobCover is available, it was also considered in our studies. The best results can be expected when using the land cover data with the highest spatial (and thematic) resolution that is available for the site. It is also very important to consider the climatic and terrain related conditions of the area of interest (see section 3.3).

The result of the application of the land cover based PS assessment method is a map of the expectable PS density of the area of interest as shown in Fig. 4b. As explained in section 1, successful PSI processing requires a minimum PS density of 3 to 4 PS per $\mathrm{km}^{2}$ to be able to reconstruct and compensate the APS (Colesanti et al., 2003b). Especially at SAR data recorded by middle spatial resolution SAR sensors working at C-band or L-band (e.g. ERS, ENVISAT, Radarsat (esp. Standard mode) or ALOS PALSAR) densely vegetated areas or high mountainous areas (layover/shadow effects, etc. see section 3.3) achieve PS density values within or even below this critical value. 
Please note that this manuscript has been published in ISPRS Journal of Photogrammetry and Remote Sensing http://dx.doi.org/10.1016/j.isprsjprs.2013.09.001:

Simon Plank, John Singer, Kurosch Thuro: Assessment of number and distribution of persistent scatterers prior to radar acquisition using open access land cover and topographical data. ISPRS Journal of Photogrammetry and Remote Sensing 85 (2013) 132-147.

Moreover, for meaningful PSI applications which enable detailed analysis of e.g. single parts within a landslide, much higher PS density values than the aforementioned critical value are required. Therefore, the presented PS assessment method is a very useful tool to evaluate the applicability of PSI for monitoring the AOI prior to its SAR recording.

In future, the statistical power of the relative PS(\&DS) density graphs could be increased by using data of more sites. This is especially meaningful for the assessment of DS\&PS as its graph is based on 'only' eight datasets until now. Furthermore, as the better suited CORINE dataset is only available in Europe, for other continents the relative PS(\&DS) method density using other higher spatial and thematic resolution land cover data should be applied (e.g. Africover, a land cover dataset of ten African countries; for more information see: http://www.africover.org.)

\section{PS assessment based on topographical maps and OpenStreetMap data 4.1 Topographical maps used}

Contrary to the aforementioned PS assessment method the one described in this section not only enables the determination of the PS density by using topographical maps (TM) and OpenStreetMap (OSM) data, but also the calculation of the distances between the assessed PS targets and their distribution within the site - prior to its radar recording. This method was applied at different types of TMs with different map scales ranging from 1:200,000 to 1:25,000. We used national and international maps (e.g. soviet (Russian) military maps) of different formats: paper, scans, digital raster and vector data. The map scale of the TM is required to be 1:200,000 or larger to show enough details for the PS assessment method. However, at the sites North Germany, Piedmont and Netherlands only Russian TMs at a map scale of 1:500,000 or smaller were freely available. Therefore, it was not possible to apply the PS assessment method based on TMs at these sites. As described in section 4.2.1 in more detail, this PS assessment method considers man-made objects as possible PS targets, as only these artificial objects, such buildings, etc. are mapped within a TM. The quality of the results of this PS assessment strongly depends on the accuracy and map scale of the TM. For instance, at a map scale of 1:500,000 only a single point symbolizes an entire city, whereas at a map scale of 1:200,000 a TM generally shows blocks of houses. Larger map scales even show single houses. OSM data was used at all sites (except of the Cairo site) for the PS assessment. It can be downloaded free of charge at e.g. http://download.geofabrik.de/osm/.

\subsection{PS assessment using TM and OSM data: method}

\subsubsection{Theory}

As man-made objects are significant sources of PS targets (Ferretti et al., 2000a; b; 2001; Colesanti et al., 2003a; Hanssen, 2005; Refice et al., 2005; Vilardo et al., 2009), in a GIS objects working as possible PS, such as buildings, larger roads, railroads, etc., were extracted from TM and OSM data. Roads or railroads do not directly work as PS targets, but they 'contain' for example road signs, or overhead line masts, respectively, working as PS targets. As most TMs do not contain natural PS objects, such as single rocks, etc., this type of PS objects cannot be extracted from these maps.

Depending on the type of the TM available for the site, different preparation work is necessary. Vector data can be used directly as input data for the PS assessment procedure, whereas raster data needs to be vectorized. This vectorization can easily be applied for digital raster data, but for scanned topographical maps costly half-automated vectorization is necessary (manually elimination of disturbing map objects, such as labels, grids, contour lines, etc.). The developed procedure for PS assessment using TM and OSM data works as follows (Fig. 7): First, possible PS objects, such as buildings, roads and rail roads, were extracted from the TM and OSM data. Then, the number of possible PS of the site was determined, depending on the spatial resolution of the SAR sensor used. This is achieved by selecting all cells of a raster (with a spatial resolution equal to the one of the SAR sensor) that intersect with a 
Please note that this manuscript has been published in ISPRS Journal of Photogrammetry and Remote Sensing http://dx.doi.org/10.1016/j.isprsjprs.2013.09.001:

Simon Plank, John Singer, Kurosch Thuro: Assessment of number and distribution of persistent scatterers prior to radar acquisition using open access land cover and topographical data. ISPRS Journal of Photogrammetry and Remote Sensing 85 (2013) 132-147.

possible PS object. After that, the PS density (PS per km², Eq. (1)) was calculated, using the number of assessed PS and the area of the site (see also section 4.2.2 for a more detailed description of the procedure).

In general, buildings show a higher probability to form PS than roads and rail roads, as on the latter there are less possible PS targets, such as road signs or overhead line masts. To enable the user to separate these different sources of possible PS - which might also have different qualities -, we developed a double-stage PS assessment procedure: First, possible PSs are assessed using only the TM applying the procedure described above. That means, from the TM only the buildings are extracted as possible PS objects. Second, road and rail road data from the OSM are extracted and then used as additional possible PS sources. Another reason for this double-stage procedure is that roads and rail roads are falsely enlarged depending on the TM's scale. The big advantage of the OSM data is that they storage roads and rail roads as vector data (polylines). This data can easily be used as input for the PS assessment. To get more realistic PS assessment results, we generated a buffer zone depending on the type of road or railroad around each polyline, representing the width of the roads and the gauge of the rail roads, respectively. As shown in section 4.3, one achieves two results. The first PS assessment result is based on only the buildings as possible PS objects, while the second one additionally considers roads and rail roads.

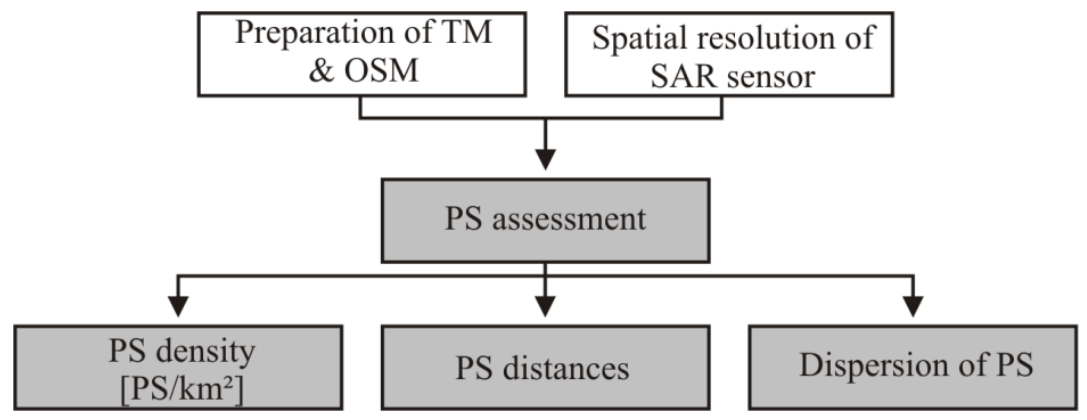

Fig. 7: The procedure of PS assessment using TM and OSM data.

According to Adam (2011), to ensure optimal PSI processing - enabling reconstruction and compensation of the atmospheric phase screen (APS) - the maximal distance between two PS should be less than $700 \mathrm{~m}$. In an extreme case a PSI processing is also possible for a PS distance of ca. 1,000 m (Adam et al., 2011), or according to Zebker et al. (2007), even 2,000 m. These values are a rule of thumb - not fixed values. The amount of the atmospheric influence is very important for the maximum PS distance. Therefore, the Euclidean distance between the assessed PS is calculated (Eq. 3). PSI processing constructs a network between the PS. It is important that all PS can be combined into the network. The aforementioned Euclidean distance map enables the user to easily detect isolated PS targets or clusters of PSs that cannot be included into the overall PS network of the site because of their too large distance to the nearest PS of the network.

To test whether the assessed PS are clustered at certain locations or more regularly distributed within the site which would be the optimal case to get evenly distributed deformation measurements of the entire AOI -, using the nearest neighbor analysis (NNA) method the distribution of the assessed PS was analyzed. In this analysis an empirical point pattern (the assessed PS points) is statistically compared with a theoretical point pattern (random distribution) (Chen and Getis, 1998).

The NNA calculates for each empirical point $i$ (coordinates $x_{i} / y_{i}$ ) the Euclidean distance $d_{i j}$ to the nearest point $j$ $\left(x_{j} / y_{j}\right)$ (Vasiliev, 1996) (Eq. (3)).

$$
d_{i j}=\sqrt{\left(x_{i}-x_{j}\right)^{2}+\left(y_{i}-y_{j}\right)^{2}}
$$


Please note that this manuscript has been published in ISPRS Journal of Photogrammetry and Remote Sensing http://dx.doi.org/10.1016/j.isprsjprs.2013.09.001:

Simon Plank, John Singer, Kurosch Thuro: Assessment of number and distribution of persistent scatterers prior to radar acquisition using open access land cover and topographical data. ISPRS Journal of Photogrammetry and Remote Sensing 85 (2013) 132-147.

Afterwards, these distances are arithmetically averaged over the number $M$ of assessed PS points (Eq. (4)).

$$
d_{\text {averaged }}=\frac{1}{M} \sum_{i=1}^{M} d_{i j}
$$

Then, the arithmetically averaged distance $r_{\text {averaged }}$ of the random point pattern is calculated (Eq. (5)). $A$ is the area of the site.

$$
r_{\text {averaged }}=\frac{1}{2 \sqrt{\frac{M}{A}}}
$$

The quotient $Q$ of the Eqs. (4) and (5) compares the distribution of the empirical and the random point pattern (Eq. (6)).

$$
Q=\frac{d_{\text {averaged }}}{r_{\text {averaged }}}=2 \frac{1}{M} \sum_{i=1}^{M} d_{i j} \cdot \sqrt{\frac{M}{A}}
$$

If $Q$ is equal to 1 , the arithmetically averaged distances of both point patterns are equal. The empirical point pattern corresponds to a random distribution. $Q>1$ indicates a regular pattern of the empirical points, whereas $Q<1$ is equal to a clustered pattern. At $Q=0$ all points are concentrated to one location. As the size of area $A$ has a strong influence on the result of the NNA, we set $A$ equal to the area of the site.

\subsubsection{The procedure of PS assessment using TM and OSM data}

Here, we explain step by step the aforementioned PS assessment procedure (section 4.2.1) which was implemented in a GIS. Fig. 8a shows the original TM of the city Courmayeur (site Aosta Valley; 1:25,000). In the preparation step possible PS objects (e.g. buildings, roads, etc.) were extracted from the TM and OSM data. In the next step, a raster with a cell size equal to the spatial resolution of the SAR sensor was laid over the entire site (Fig. 8c). Then, all raster cells intersecting with at least one possible PS object (e.g. a building) were selected (Fig. 8d) as the assessed PS. Afterwards, the Euclidean distance between the assessed PS was calculated (Fig. 8e) and classified regarding to the usability for PSI processing. This was implemented by calculating buffer zones of the half value of the maximum PS distances around each assessed PS, as described in section 4.2.1. Calculating the half value of the maximum PS distances for the buffer zones ensures that the absolute distance between two neighboring PS located within the same buffer zone is less or equal than the corresponding maximum PS distance. Due to the small map excerpt of Fig. 8e, only the buffer zones of the Euclidean distances ' $<350 \mathrm{~m}$ ' and '> $350 \mathrm{~m}$ to $500 \mathrm{~m}$ ' are shown. Finally, the NNA was executed for the site to analyze the distribution of the assessed PS.

Fig. 9 shows the Euclidean distance calculation of an excerpt of the Bavaria site. Here, all in section 4.2.1 defined intervals of the Euclidean distance are represented. One recognizes two clusters of assessed PS at Fig. 9. These PS are originated by buildings which are located at both banks of Lake Starnberg. The PS clusters of the east and west side of the lake cannot be connected into a common PS network due to their large distance of more than $4 \mathrm{~km}$ between each other. This low connectivity of the assessed PS complicates the applicability of PSI. 
Please note that this manuscript has been published in ISPRS Journal of Photogrammetry and Remote Sensing http://dx.doi.org/10.1016/j.isprsjprs.2013.09.001:

Simon Plank, John Singer, Kurosch Thuro: Assessment of number and distribution of persistent scatterers prior to radar acquisition using open access land cover and topographical data. ISPRS Journal of Photogrammetry and Remote Sensing 85 (2013) 132-147.
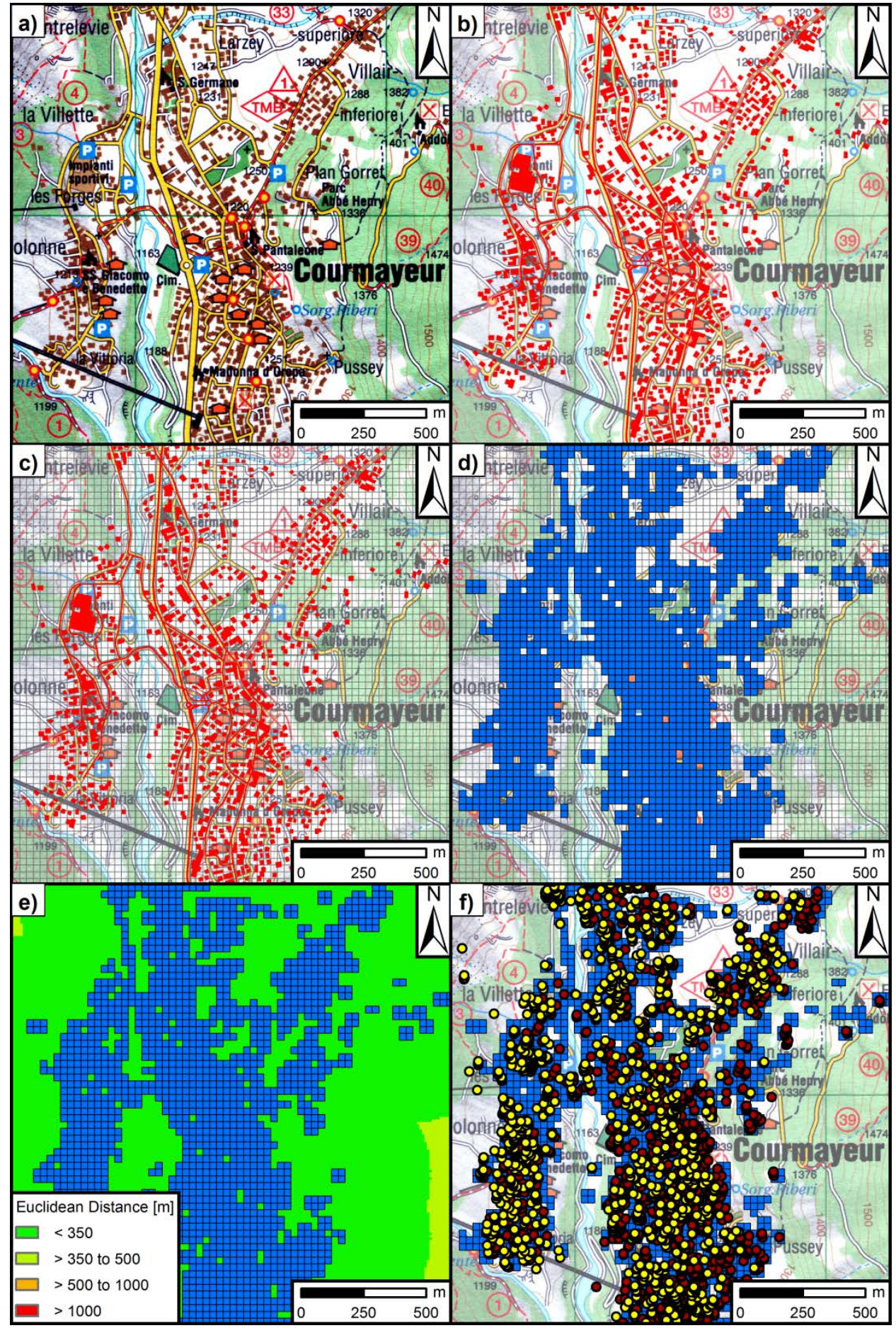

Fig. 8. Original topographical map (a). Result of TM and OSM preparation (b). Raster over site (c). Raster cells selected: assessed PS (d). Euclidean distance between assessed PS (e). Here, the buffer zones represent the half value of the maximum PS distances to ensure that the absolute distance between two neighboring PS located within the same buffer zone is less or equal than the corresponding maximum PS distance (see section 4.2.1). Validation of PS assessment with real PS targets (ascending: yellow/light; descending: red/dark) (f). 
Please note that this manuscript has been published in ISPRS Journal of Photogrammetry and Remote Sensing http://dx.doi.org/10.1016/j.isprsjprs.2013.09.001:

Simon Plank, John Singer, Kurosch Thuro: Assessment of number and distribution of persistent scatterers prior to radar acquisition using open access land cover and topographical data. ISPRS Journal of Photogrammetry and Remote Sensing 85 (2013) 132-147.

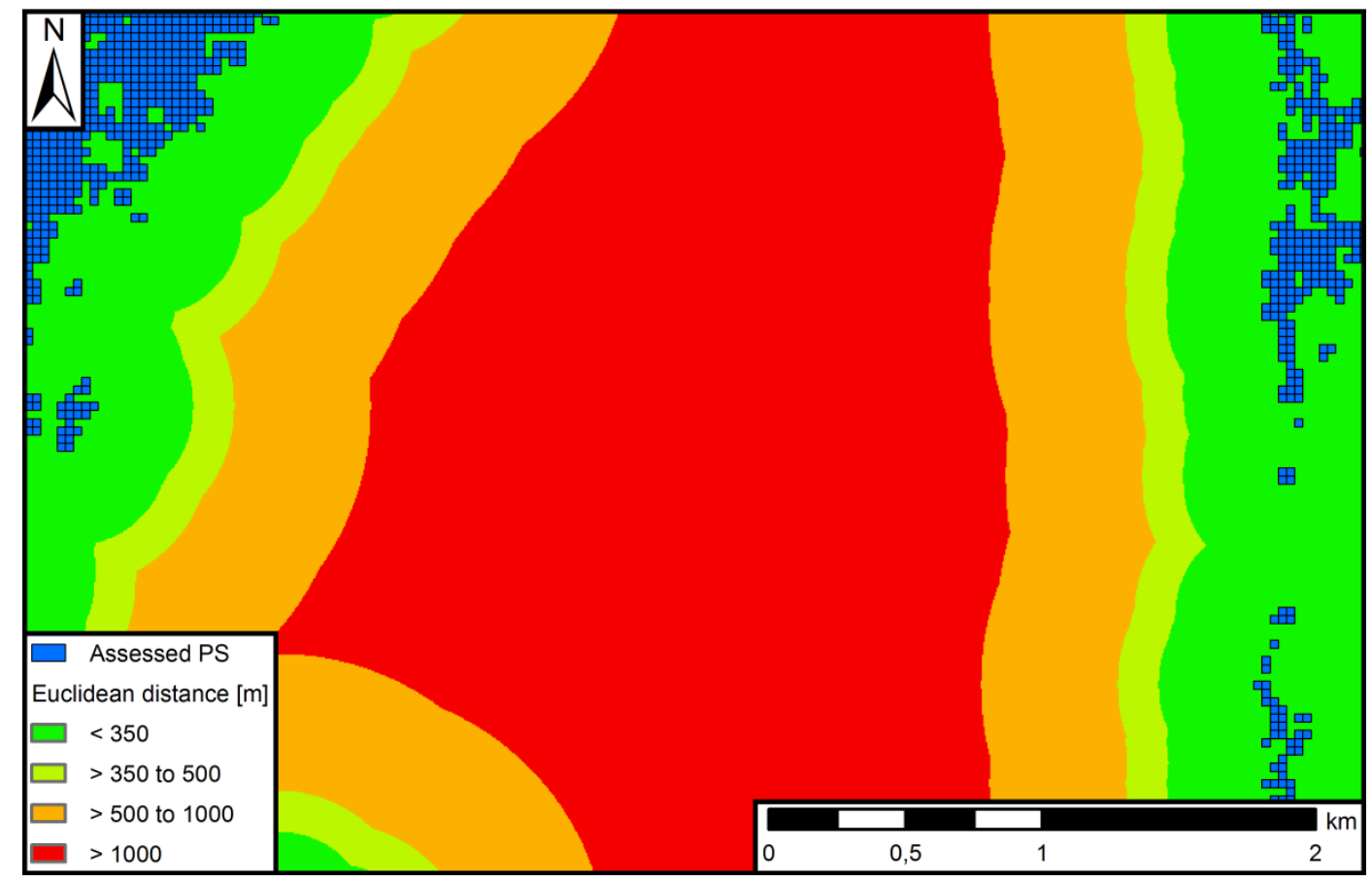

Fig. 9. Classification of the Euclidean distance between the assessed PS at Lake Starnberg, southwest of Munich (excerpt of the Bavaria site). The buffer zones represent the half value of the maximum PS distances to ensure that the absolute distance between two neighboring PS located within the same buffer zone is less or equal than the corresponding maximum PS distance (see section 4.2.1). The distance between the clusters of the assessed PS located at the west side and at the east side of Lake Starnberg is larger than $4 \mathrm{~km}$. This large distance complicates the connection of the PS clusters into a common PS network and demonstrates an example of a low applicability of PSI.

\subsection{PS assessment using TM and OSM data: results}

The PS assessment method described in section 4.2 was executed for all aforementioned sites. Thereby, the PS assessment was done twice for each site: once by only using the TM and once by using both the TM and OSM data. This twofold execution of the PS assessment procedure made it possible to test whether the quality of the results can be improved by additionally using OSM data.

As an example for all sites the results of the Aosta Valley site are shown in this paper. Fig. 8 shows a part of this site. When using only the TM, the assessed PS were restricted to the settlement areas. Therefore, more and larger areas exceeding the maximal Euclidean distance between two PS could be identified. The assessed PS density was ca. $182 \mathrm{PS} / \mathrm{km}^{2}$.

This PS density increased by about $31 \%$ (up to ca. $239 \mathrm{PS} / \mathrm{km}^{2}$ ) when both the TM and OSM data were used for extraction of the possible PS objects. As additionally roads and railroads (containing road signs or overhead line masts, respectively) were considered as possible PS objects when using OSM data, also the number and areas exceeding the maximal PS distance decreased.

The results of the NNA show a $Q$ value of 0.73 and 0.83 for 'only considering the TM' and 'TM \& OSM', respectively. The $Q$ value of less than 1 confirms the visual interpretation of Fig. 8d: the assessed PS show strong clustering in the city area. 
Please note that this manuscript has been published in ISPRS Journal of Photogrammetry and Remote Sensing http://dx.doi.org/10.1016/j.isprsjprs.2013.09.001:

Simon Plank, John Singer, Kurosch Thuro: Assessment of number and distribution of persistent scatterers prior to radar acquisition using open access land cover and topographical data. ISPRS Journal of Photogrammetry and Remote Sensing 85 (2013) 132-147.

\subsection{Validation with real PS data}

For the validation of the PS assessment results real PS datasets (processed PS) were used (Tab. 1, Fig. 8f). The validation addresses two questions concerning the PS assessment results:

1) What percentage of the real PS is detected by the assessed PS?

2) How great is the probability of an assessed PS being a real PS?

The first question determines the quality of the PS assessment, the percentage of the real PS detected by the assumed possible PS objects (buildings etc.). The second question - the probability of an assessed PS being a real PS - is intended to be used at new sites for which SAR data is not yet available.

The results of the first validation question show that the percentage of real PS detected by the assessed one is for all sites higher when considering OSM data as in this case more possible PS objects were considered (Fig. 10). As already mentioned in section 4.2.1, most TMs do not contain natural possible PS objects, such as single rocks. Therefore, these natural PS targets cannot be considered in the developed PS assessment procedure. This concerns especially the Cairo site, where a section of the site is characterized by a stony and rocky desert, which shows very good properties to form PS targets. However, as these single rocks are not mapped in the used TM, they cannot be assessed as possible PS targets using the TM and OSM based PS assessment method. Consequently, the Cairo site shows a distinctively low value for the processed PS detected by the assessed one (Fig. 10).

Another reason for this low value of the Cairo site is the small map scale of 1:200,000 of the map used here. Due to this small map scale, the accuracy of the PS assessment is much lower as the TM shows much less details than at a larger map scale.

The detection rate values for the Bavaria site show strong variations (Fig. 10). Considering only the 'without OSM' values of this site (i.e. based on the TM only), one recognizes a strong influence of the map scale (cf. Cairo site above). Another reason for the variation of the values at the Bavaria site (considering especially the values of the same map scale 1:25,000), is the coverage of the different TMs used at this site. The values 'Bavaria TM25 full' and 'Bavaria TM 25 russ.' represent the results using a TM of map scale 1:25,000 of the entire $100 \mathrm{~km}$ times $100 \mathrm{~km}$ site and of a sub site (west half of the site), respectively. Considering the entire site and the relatively large sub site of the latter mentioned TM (' $\ldots$ russ.'), one recognizes much lower values for the percentage of processed PS detected by the assessment (Fig. 10), comparing to the one of the 'Bavaria TM25 plus' and of the 'Bayern-Map plus 25'. The area of the sub site 'Bavaria TM25 plus' and 'Bayern-Map plus 25' is a relatively small area with a much higher building density compared to the entire site. As at the entire Bavarian site (and also at the relatively large sub site ' $\ldots$ russ.') the number of natural possible PS targets, which cannot be assessed by the TM and OSM based method, is much higher than at the smaller '.. plus' sub site, also its percentage of processed PS detected by the assessment is much lower.

Fig. 11 shows the relationship of the map scale and the probability of an assessed PS being a real PS. One has to consider that not each building (or road sign, overhead line mast, etc.) is a PS target in reality. Depending on the orbit (ascending/descending) and incidence angle of the satellite, the geometry, orientation and construction material of the building, etc., a building could work as PS target or not. Furthermore, if there are two or more point scatterers located very close to each other within the same resolution cell, these point scatterers do not always work as 'good' PS. However, SAR tomography (e.g. Zhu and Bamler, 2010) is a possible way to separate different point scatterers, that are located within the same range resolution cell, e.g. due to foreshortening effects. As 'with OSM' considers more possible PS objects in the PS assessment than 'without OSM', also the probability for overestimation increases (lower values in Fig. 11).

The general trend of Fig. 11 is the increase of the probability value with increasing map scale. The strong variance and the low values at map scale 1:25,000 are due to the 'imprecise' geocoding of the real PS targets of the Bavaria site (lower values of Fig. 11). One reason for the 'imprecise' geocoding is the lower orbit accuracy of the ERS 
Please note that this manuscript has been published in ISPRS Journal of Photogrammetry and Remote Sensing http://dx.doi.org/10.1016/j.isprsjprs.2013.09.001:

Simon Plank, John Singer, Kurosch Thuro: Assessment of number and distribution of persistent scatterers prior to radar acquisition using open access land cover and topographical data. ISPRS Journal of Photogrammetry and Remote Sensing 85 (2013) 132-147.

satellites (compared to e.g. TerraSAR-X). Another influencing factor of the geocoding accuracy is the accuracy of the knowledge of the height of the reference point.

Therefore, the results of the PS assessment validation were distorted and the probability for an assessed PS being a real PS was assessed too low. For such large map scales one can assess a probability value for the Bavaria site being as high as for the Aosta valley site (higher values of Fig. 11).

The lowest values of Fig. 11 (Aschau am Inn site) show the limitation of the TM and OSM based PS assessment method for high spatial resolution SAR sensors such as TerraSAR-X. As this high spatial resolution leads to very small raster cells in the PS assessment procedure, even very small geocoding inaccuracies (few meters) distort the validation of the PS assessment. A geocoding error greater than the size of one raster cell can cause a falsely underestimation of the validation.

At high spatial resolution SAR data, an important source of the PS are the facades of buildings. The TM \& OSM based PS assessment method uses the roof area of buildings to identify possible PS objects. However, the influence of this contradiction on the result of the PS assessment can be neglected, as the TM \& OSM based PS assessment procedure correctly identifies buildings as a main source of PS. But one has to consider that there could be expected several PS within one raster cell selected as assessed PS (e.g. originated from the stories of a multi-story building).

The black dotted line of Fig. 11 shows the ideal case: only the results of sites with relatively high geocoding accuracy of the PS targets and no high spatial resolution SAR data (e.g. no TerraSAR-X data) are considered.

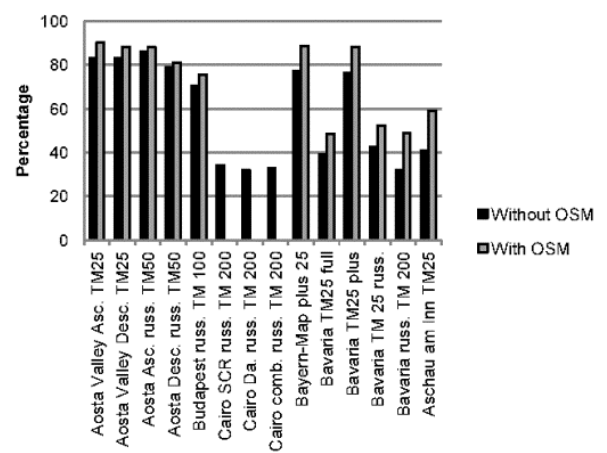

Fig. 10. Percentage of real PS detected by assessed PS. Results without (black) and with (grey) additional consideration of OSM data (not available for the Cairo site). Aosta Valley site (Asc. = Ascending; Desc. = Descending orbit; russ. TM: Russian TM), Bavaria site (full = entire site; russ. = sub site Russian TM; plus = sub site Bayern-Map plus). 
Please note that this manuscript has been published in ISPRS Journal of Photogrammetry and Remote Sensing http://dx.doi.org/10.1016/j.isprsjprs.2013.09.001:

Simon Plank, John Singer, Kurosch Thuro: Assessment of number and distribution of persistent scatterers prior to radar acquisition using open access land cover and topographical data. ISPRS Journal of Photogrammetry and Remote Sensing 85 (2013) 132-147.

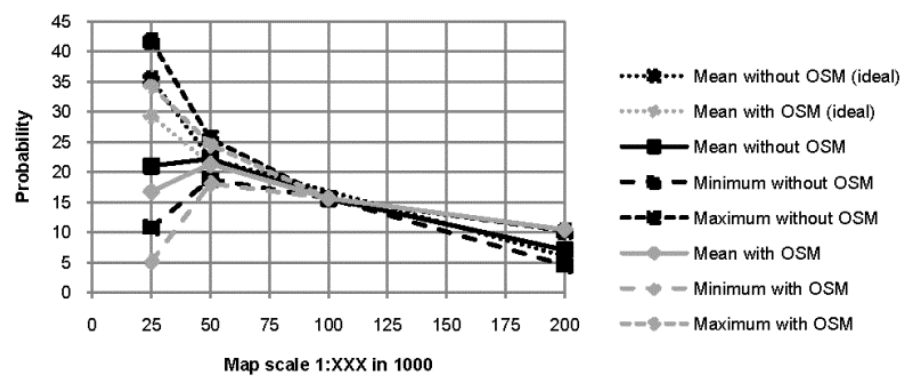

Fig. 11. Influence of the map scale (in 1:XXX; e.g. ' 25 ' $=1: 25,000$ ) on the probability of an assessed PS being a PS in reality. The probability increases with increasing map scale. The black lines show the results for 'without considering OSM', the grey lines 'with considering OSM'. The continuous line is the mean value of all sites in each case. The dashed line is the minimal and the dotted line the maximal value in each case. At the scale 1:100,000 there is only one measured value. The first line (legend) shows the ideal case (see description in the text) of the mean value 'without considering OSM' and the second line (legend) shows the ideal case of the mean value 'with considering OSM' (data only available for the map scales 1:25,000 and 1:50,000).

\subsection{Conclusion of the TM and OSM based PS assessment method - benefits for the user}

When applying the PS assessment method based on the TM and OSM data, the user achieves several maps. The first result is the expectable PS density of the area of interest (see also Fig. 8d). To compensate for the influence of the map scale of the used TM, one has to multiply the assessed PS density by the corresponding percentage value as described in section 4.4 (Fig. 11). This is necessary, as not each building always works as a PS in reality. As mentioned above, influencing factors are the incidence angle and pass direction of the SAR sensor, the geometry, orientation and construction material of the building, etc. See also section 3.5 regarding the required PS density for successful PSI application.

The second result of the developed PS assessment method is the determination of the distance between the assessed PS. A classified Euclidean distance map like the one of Fig. 8e) or 9 enables the user to quickly investigate, whether there are clusters of assessed PS which cannot be connected to the overall PS network.

The result of the NNA (see section 4.2.1) is an overview of the distribution of the assessed PS to be able to analyze whether the PS are regularly distributed within the AOI (which would be the ideal case for deformation analysis), or whether the PS are clustered at certain locations.

\section{Discussion and conclusion}

Reliable PSI processing requires a stack of at least 15 to 50 SAR images. This makes processing very timeconsuming and costly. Successful PSI application needs a sufficiently high number of PS within the site. However, an assessment of these PS prior to the processing of several SAR images is very difficult. Therefore, we presented two new methods for assessing persistent scatterers (PS), prior to the radar recording of the area of interest (AOI). Fig. 12 shows the decision diagram for the application of the two new developed PS assessment methods. The first method uses freely available land cover data (GlobCover and CORINE). Prerequisite for the application of this method is an assessment or information about the absolute PS density in the reference class urban area of a site recorded by the same or comparable SAR sensor and processed by the same or comparable PS processing method as planned for the AOI. When considering the climatic properties of the site, this PS assessment method can be applied world-wide. The method is a fast tool to get an overview of the expected PS density of large areas. For instance using CORINE, the PS density for the entire European continent could be assessed for a given SAR sensor and PS processing method. 
Please note that this manuscript has been published in ISPRS Journal of Photogrammetry and Remote Sensing http://dx.doi.org/10.1016/j.isprsjprs.2013.09.001:

Simon Plank, John Singer, Kurosch Thuro: Assessment of number and distribution of persistent scatterers prior to radar acquisition using open access land cover and topographical data. ISPRS Journal of Photogrammetry and Remote Sensing 85 (2013) 132-147.

The validation with real PS data showed that CORINE land cover data can be applied very good for predicting the PS density. The difference between the assessed and processed PS density is very low for CORINE (see section 3.4). Over $63 \%$ of the entire site shows differences of less than $\pm 20 \mathrm{PS} / \mathrm{km}^{2}$. Due to its lower spatial resolution GlobCover is not as good suited as CORINE for PS density assessment. Using the GlobCover land cover dataset, the validation shows a percentage of about $48 \%$ for the interval $\pm 20 \mathrm{PS} / \mathrm{km}^{2}$ for the difference of assessed and processed PS density. Therefore, the CORINE dataset should be preferred for European sites.

The validation shows a stronger overestimation for the DS\&PS density assessment than for the corresponding PS density assessment. The DS\&PS density assessment based on the CORINE land cover data (ca. $47 \%$ within the $\pm 20 \mathrm{DS} \& \mathrm{PS} / \mathrm{km}^{2}$ interval) is almost as good as the PS density assessment based on GlobCover. However, the DS\&PS density assessment using the GlobCover land cover dataset shows a very high tendency for overestimation (over $50 \%$ of the site's area show a difference of assessed and processed DS\&PS density of $>20$ DS\&PS/ $/ \mathrm{km}^{2}$ ).

The investigation of the relative deviation of the assessed and processed PS density (Eq. 2; Fig. 6) showed especially at low PS density land cover classes a trend for overestimation of the PS density. At these areas (e.g. densely vegetated areas) the developed method is only able to assess the magnitude of the expectable PS density, but not its absolute number. Nevertheless, the land cover based PS assessment method enables the user to get a fast and useful overview of the expectable PS density of the AOI prior to its SAR recording.

The second method described in the paper uses freely available and low-cost topographical maps (TM) and OpenStreetMap data to assess possible PS targets. For this method a TM of map scale greater than 1:200,000 for the AOI is required. The advantages of this method are that (1) contrary to the aforementioned PS assessment method no results of PSI processing of another site are required and (2) not only the density of the predicted PS of the site is determined, but also the distances between the assessed PS are calculated and classified regarding to their influence on the applicability of PSI and their distribution within the site is analyzed. Therefore, this method enables more detailed analysis of the assessed PS than the aforementioned technique. The amount of preparation work of this PS assessment method depends on the type of TM used. TMs represented as digital vector data can directly be used as an input of the calculation. Other types of TMs, such as digital raster data or scanned paper maps, require work intensive preparation of the TM (e.g. extraction of interesting map features or elimination of disturbing features such as labels, respectively). Therefore, if no digital vector TM is available, the method is best suited for smaller sites e.g. for monitoring landslides.

The TM and OSM data based PS assessment method was validated using real PS data. We applied two validation questions. The investigation of the first one, 'What percentage of the real PS is detected by the assessed PS?' showed that the additional use of OSM data increases this percentage value, as in this case more possible PS targets are considered in the assessment (Fig. 10). The value of the percentage of processed PS detected by the assessment depends on the map scale of the TM used. For instance, at the Cairo site (map scale 1:200,000) this percentage is with ca. 33 \% very low, while at the Aosta Valley site (map scale 1:25,000) this percentage is up to $83 \%$.

The second validation question is 'How great is the probability of an assessed PS being a real (processed) PS?'. It is important to notice that not each building (or road sign, etc.) always functions as a PS target in reality. Important factors for this are the imaging geometry of the satellite (pass direction and incidence angle), the geometry, orientation and construction material of the building, etc. As the TM shows more details with increasing map scale, also the probability of an assessed PS working as a PS in reality increases when using maps of a larger map scale. This probability value is very low (ca. $5.5 \% \pm 2 \%$ ) at a map scale of 1:200,000. It increases to about $22.1 \%$ ( $\pm 3.4 \%$ ) for a map scale of $1: 50,000$ and to about $35.4 \%$ ( $\pm 6.3 \%$ ) for a map scale of $1: 25,000$ (considering the ideal case of Fig. 11). These probability values are intended to be used at new sites, where SAR data is not yet available.

In the ideal case - the prerequisites of all two PS assessment methods are fulfilled - all two methods should be applied, starting with the first one based on land cover data to get an overview of the expected PS density of the AOI - even for large areas. The land cover based PS density assessment method can be applied very fast. It considers all 
Please note that this manuscript has been published in ISPRS Journal of Photogrammetry and Remote Sensing http://dx.doi.org/10.1016/j.isprsjprs.2013.09.001:

Simon Plank, John Singer, Kurosch Thuro: Assessment of number and distribution of persistent scatterers prior to radar acquisition using open access land cover and topographical data. ISPRS Journal of Photogrammetry and Remote Sensing 85 (2013) 132-147.

possible PS and DS targets. Its spatial resolution depends on the one of the land cover dataset used, which is $100 \mathrm{~m}$ for CORINE 2006 and $300 \mathrm{~m}$ for GlobCover 2009.

In the next step, by applying the second PS assessment method based on TM and OSM data one receives the most detailed information about the expected PS targets, including their density, distances and distribution within the site. However, the accuracy of the PS assessment of this method strongly depends on the map scale of the TM used. Due to the map content, the TM and OSM based PS assessment method is only able to consider artificial objects as possible PS targets (e.g. road signs, overhead line masts, buildings, etc.). Consequently, this PS assessment method strongly underestimates the PS density in areas dominated by natural PS targets (e.g. rocky and stony desert areas). Therefore, especially in those areas, also the first PS assessment method based on the land cover data should be applied, to get additional information on natural PS targets.

The advantage of the PS assessment methods presented in this paper in comparison to already existing procedures is that the former enable a prediction of possible PS prior to the radar recording of the site, while the latter require a stack of already recorded SAR data. The presented PS assessment methods are based on freely available geodata and can quickly be executed to enable cost and time effective pre-survey suitability analysis of the PSI approach prior to its processing.

In future, the statistical power of the relative PS(\&DS) density graphs could be increased by using data of more sites. This is especially meaningful for the assessment of DS\&PS. Moreover, as the better suited CORINE dataset is only available in Europe, for other continents the relative PS(\&DS) density using other higher spatial and thematic resolution land cover data (e.g. Africover) should be applied. Moreover, a web-processing service for the two PS assessment methods - especially the one based on the TM and OSM data - could be developed.

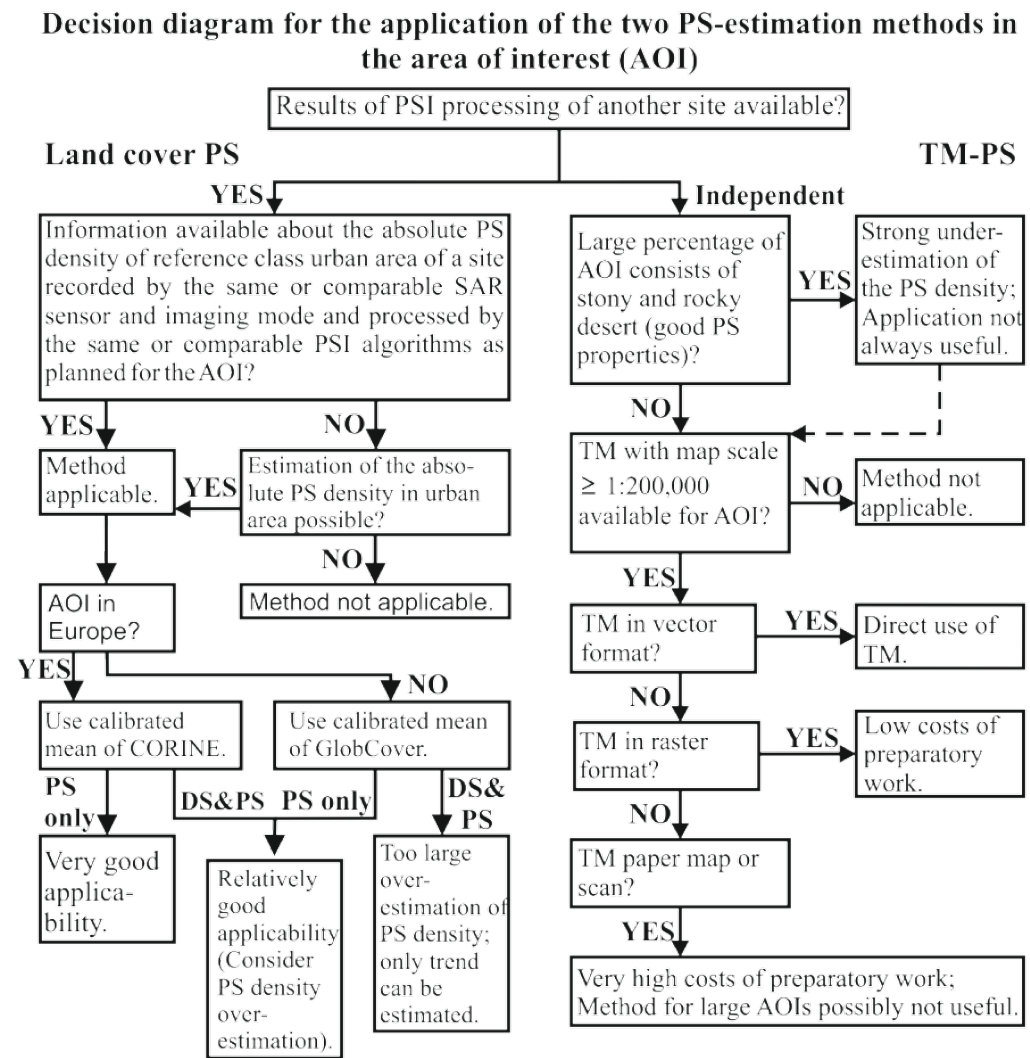

Fig. 12. Decision diagram for the application of the two PS assessment methods in the area of interest (AOI). 
Please note that this manuscript has been published in ISPRS Journal of Photogrammetry and Remote Sensing http://dx.doi.org/10.1016/j.isprsjprs.2013.09.001:

Simon Plank, John Singer, Kurosch Thuro: Assessment of number and distribution of persistent scatterers prior to radar acquisition using open access land cover and topographical data. ISPRS Journal of Photogrammetry and Remote Sensing 85 (2013) 132-147.

\section{Acknowledgements}

The authors would like to thank A. Ferretti (Tele-Rilevamento Europa - T.R.E), M. Riedmann and O. Lang (both Astrium Infoterra), W. Liebhart (German Aerospace Center - DLR), M. Foumelis (ESA) and M. C. Cuenca (Delft University of Technology) for providing the PS targets data of the sites. The authors gratefully acknowledge the support of the TUM Graduate School's Faculty Graduate Center BGU at the Technische Universität München and thank the Universität Bayern e.V. for financial support.

\section{References}

Adam, N., Gonzalez, F.R., Parizzi, A., Liebhart, W., 2011. Wide area persistent scatterer interferometry. In: Proc. IEEE IGARSS 2011, Vancouver, BC, Canada, 24-29 July, pp. 1481-1484.

Adam, N., 2011. Private communication. At Fringe 2011, Frascati, Italy, 22 September 2011.

Barbieri, M., Lichtenegger, J., 2005. Introduction to SAR for Geology. In: K. Fletcher (Ed.), Space radar applications in Geology. An introduction to imaging radar, and application examples of ERS SAR in Geology and Geomorphology, ESA TM-17, ESA Publications Division, Noordwijk, pp. 1-54.

Bovenga, F., Wasowski, J., Nitti, D.O., Nutricato, R., Chiaradia, M. T., 2012. Using COSMO/SKYMed X-band and ENVISAT C-band SAR interferometry for landslides analysis. Remote Sensing of Environment 119, 272-285.

Cascini, L., Peduto, D., Fornaro, G., Lanari, R., Zeni, G., Guzzetti, F., 2009. Spaceborne Radar Interferometry for Landslide Monitoring. In: Proc. $1^{\text {st }}$ Italian workshop on landslides, Naples, Italy, 8-10 June, pp. 138-144.

Chen, M.D., Getis, A., 1998. Point Pattern Analysis, http://www.nku.edu/ longa/geomed/ppa/doc/html/ppa.html. (Accessed 08 August, 2013).

Cigna, F., Osmanoğlu, B., Cabral-Cano, E., Dixon, T.H., Ávila-Olivera, J.A., Garduño-Monroy, V.H., DeMets, C., Wdowinski, S., 2012. Monitoring land subsidence and its induced geological hazard with Synthetic Aperture Radar Interferometry: A case study in Morelia, Mexico. Remote Sensing of Environment 117, 146-161.

Colesanti, C., Ferretti, A., Novali, F., Prati, C., Rocca, F., 2003a. SAR Monitoring of Progressive and Seasonal Ground Deformation Using the Permanent Scatterers Technique. IEEE Transactions on Geoscience and Remote Sensing 41 (7), 1685-1701.

Colesanti, C., Ferretti, A., Prati, C., Rocca, F., 2003b. Monitoring landslides and tectonic motions with the Permanent Scatterers Technique. Engineering Geology 68 (1-2), 3-14.

Colesanti, C., Wasowski, J., 2006. Investigation landslides with space-borne Synthetic Aperture Radar (SAR) interferometry. Engineering Geology 88 (3-4), 173-199.

Cong, X., Eineder, M., Gernhardt, S., Minet, C., 2010. Diverse methods to monitoring volcanic deformation based on SAR interferometry. In: Proc. IEEE IGARSS 2010, Honolulu, HI, USA, 25-30 July, pp. 661-664.

Crosetto, M., Monserrat, O., Iglesias, R., Crippa, B., 2010. Persistent Scatterer Interferometry: Potential, Limits and Initial C- and X-band Comparison. Photogrammetric Engineering and Remote Sensing 76 (9), 1061-1069.

Fan, J., Zhao, H., Tu, P., Wang, Y., Guo, X., Ge, D., Liu, G., 2010. CRInSAR for landslide deformation monitoring: A case study in Threegorges Area. In: Proc. IEEE IGARSS 2010, Honolulu, HI, USA, 25-30 July, pp. 3956-3959. 
Please note that this manuscript has been published in ISPRS Journal of Photogrammetry and Remote Sensing http://dx.doi.org/10.1016/j.isprsjprs.2013.09.001:

Simon Plank, John Singer, Kurosch Thuro: Assessment of number and distribution of persistent scatterers prior to radar acquisition using open access land cover and topographical data. ISPRS Journal of Photogrammetry and Remote Sensing 85 (2013) 132-147.

Ferretti, A., Prati, C., Rocca F., 2000a. Analysis of Permanent Scatterers in SAR Interferometry. In: Proc. IEEE IGARSS 2000, Vol. 2, Honolulu, HI, USA, 24-28 July, pp. 761-763.

Ferretti, A., Prati, C., Rocca F., 2000b. Nonlinear Subsidence Rate Estimation Using Permanent Scatterers in Differential SAR Interferometry. IEEE Transactions on Geoscience and Remote Sensing 38 (5), 2202-2212.

Ferretti, A., Prati, C., Rocca F., 2001. Permanent scatterers in SAR interferometry. IEEE Transactions on Geoscience and Remote Sensing 39 (1), 8-20.

Ferretti, A., Perissin, D., Prati, C., Rocca, F., 2005. On the physical nature of SAR Permanent Scatterers. In: Proc. 2005 URSI Commission F Symposium on Microwave Remote Sensing of the Earth, Oceans, Ice, and Atmosphere, Ispra, Italy, 20-21 April.

Ferretti, A., Fumagalli, A., Novali, F., Prati, C., Rocca, F., Rucci A., 2011. A New Algorithm for Processing Interferometric Data-Stacks: SqueeSAR. IEEE Transactions on Geoscience and Remote Sensing 49 (9), 3460-3470.

Hanssen, R.F., 2005. Satellite radar interferometry for deformation monitoring: a priori assessment of feasibility and accuracy. International Journal of Applied Earth Observation and Geoinformation 6 (3-4), 253-260.

Heleno, S.I.N., Oliveira, L.G.S., Henriques, M.J., Falcão, A.P., Lima, J.N.P., Cooksley, G., Ferretti, A., Fonseca, A. M., Lobo-Ferreira, J.P., Fonseca, J.F.B.D., 2011. Persistent Scatterers Interferometry detects and measures ground subsidence in Lisbon. Remote Sensing of Environment 115 (8), 2152-2167.

Hooper, A., Prata, F., Sigmundsson, F., 2012. Remote Sensing of Volcanic Hazards and Their Precursors. In: Proc. of the IEEE 100 (10), 2908-2930.

Hung, W.C., Hwang, C., Chen, Y.A., Chang, C.P., Yen, J.Y., Hooper, A., Yang, C.Y., 2011. Surface deformation from persistent scatterers SAR interferometry and fusion with leveling data: A case study over the Choushui River Alluvial Fan, Taiwan. Remote Sensing of Environment 115 (4), 957-967.

Kampes, B.M., 2006. Radar interferometry - Persistent Scatterer Technique, Springer, Dordrecht.

Ketelaar, V.B.H., 2009. Satellite Radar Interferometry - Subsidence Monitoring Techniques, Springer, New York.

Lauknes, T.R., Shanker, A.P., Dehls, J.F., Zebker, H.A., Henderson, I.H.C., Larsen, Y., 2010. Detailed rockslide mapping in northern Norway with small baseline and persistent scatterer interferometric SAR time series methods. Remote Sensing of Environment 114 (9), 2097-2109.

Lillesand, T.M., Kiefer, R.W., 2000. Remote Sensing and Image Interpretation, fourth ed. John Wiley \& Sons Inc., New York.

Massironi, M., Zampieri, D., Bianchi, M., Schiavo, A., Franceschini, A., 2009. Use of PSInSAR ${ }^{\mathrm{TM}}$ data to infer active tectonics: Clues on the differential uplift across the Giudicarie belt (Central-Eastern Alps, Italy). Tectonophysics 476 (1-2), 297-303.

Metternicht, G., Hurni, L., Gogu, R., 2005. Remote sensing of landslides: An analysis of the potential contribution to geo-spatial systems for hazard assessment in mountainous environments. Remote Sensing of Environment 98 (2-3), 284-303. 
Please note that this manuscript has been published in ISPRS Journal of Photogrammetry and Remote Sensing http://dx.doi.org/10.1016/j.isprsjprs.2013.09.001:

Simon Plank, John Singer, Kurosch Thuro: Assessment of number and distribution of persistent scatterers prior to radar acquisition using open access land cover and topographical data. ISPRS Journal of Photogrammetry and Remote Sensing 85 (2013) 132-147.

Ng, A.H.M., Ge, L., Zhang, K., Li, X., 2011. Subsidence revealed by PSI technique in the Jarkarta City, Indonesia. In: Proc. IEEE IGARSS 2011, Vancouver, BC, Canada, 24-29 July, pp. 2117-2120.

Peel, M.C., Finlayson, B.L., McMahon, T.A., 2007. Updated world map of the Köppen-Geiger climate classification. Hydrology and Earth System Sciences 11 (5), 1633-1644.

Perissin, D., Prati, C., Ferretti, A., 2006. Spaceborne SAR anatomy of a city. In: Proc. Fringe 2005 Workshop: Advances in SAR Interferometry from ENVISAT and ERS missions, Frascati, Italy, 28 November - 2 December 2005, 6 p. (on CD-ROM).

Plank, S., Singer, J. Minet, C., Thuro, K., 2012. Pre-survey suitability evaluation of the differential synthetic aperture radar interferometry method for landslide monitoring. International Journal of Remote Sensing 33 (20), 6623-6637.

Refice, A., Bovenga, F., Nutricato, R., Chiaradi, M.T., Wasowski J., 2005. Land-cover classification-based Persistent Scatterers identification for peri-urban applications. In: Proc. IEEE IGARSS 2005, Seoul, South-Korea, 25-29 July, pp. 2668-2671.

Strozzi, T., Tosi, L., Teatini, P., Werner, C., Wegmüller, U., 2009. Monitoring land subsidence within the Venice Lagoon with SAR interferometry on trihedral corner reflectors. In: Proc. IEEE IGARSS 2009, Vol. 4, Cape Town, South Africa, 12-17 July, pp. 33-36.

Tosi, L., Teatini, P., Carbognin, L., Brancolini, G., 2009. Using high resolution data to reveal depth-dependent mechanism that drive land subsidence: The Venice coast, Italy. Tectonophysics 474 (1-2), 271-284.

Tosi, L., Teatini, P., Bincoletto, P., Simonini, P., Strozzi, T., 2012. Integrating Geotechnical and Interferometric SAR Measurements for Secondary Compressibility Characterization of Coastal Soils. Surveys in Geophysics 33 (5), $907-$ 926.

Vasiliev, I.R., 1996. Visualization and Spatial Autocorrelation. In: Arlinghaus, S.L. (Ed.), Practical Handbook of Spatial Statistics, CRC Press, Boca Raton, pp. 17-30.

Vilardo, G., Ventura, G., Terranova, C., Matano, F., Nardò, S., 2009. Ground deformation due to tectonic, hydrothermal, gravity, hydrogeological, and anthropic processes in the Campania Region (Southern Italy) from Permanent Scatterers Synthetic Aperture Radar Interferometry. Remote Sensing of Environment 113 (1), $197-212$.

Xia, Y., 2008. CR-Based SAR-Interferometry for Landslide Monitoring. In: Proc. IEEE IGARSS 2008, Vol. 2, Boston, MA, USA, 6-11 July, pp. 1239-1242.

Zebker, H.A., Shankar, P., Hooper, A., 2007. InSAR Remote Sensing Over Decorrelating Terrains: Persistent Scattering Methods. In: Proc. IEEE Radar Conference 2007, Waltham, MA, USA, 17-20 April, pp. 717-722.

Zhu, X.X., Bamler, R., 2010. Very High Resolution Spaceborne SAR Tomography in Urban Environment. IEEE Transactions on Geoscience and Remote Sensing 48 (12), 4296-4308. 